\title{
Prediction models to analyse the performance of a commercial-scale membrane distillation unit for desalting brines from RO plants
}

\author{
Juan D. Gil ${ }^{\mathrm{a}}$, Alba Ruiz-Aguirre ${ }^{\mathrm{a}}$, Lidia Roca ${ }^{\mathrm{b}}$, Guillermo Zaragoza ${ }^{\mathrm{b}, *}$, \\ Manuel Berenguel ${ }^{\mathrm{a}}$ \\ ${ }^{a}$ Centro Mixto CIESOL, ceiA3, Universidad de Almería. Ctra. Sacramento s/n, Almería \\ 04120, Spain; \{juandiego.gil,ara399,beren\}@ual.es \\ ${ }^{b}$ CIEMAT-Plataforma Solar de Almería, Ctra. de Senés s/n, Tabernas 04200, Almería, \\ Spain; \{lidia.roca,guillermo.zaragoza\}@psa.es
}

\begin{abstract}
Desalting brines from Reverse Osmosis ( $\mathrm{RO}$ ) plants is one of the most promising applications of Membrane Distillation (MD) systems. The development of accurate models to predict MD system performances plays a significant role in the design of this kind of industrial applications. In this paper, a commercialscale Permeate Gap Membrane Distillation (PGMD) module was modeled by means of two different approaches: Response Surface Methodology (RSM) and Artificial Neural Networks (ANN). Condenser inlet temperature, evaporator inlet temperature, feed flow rate and feed water salt concentration were selected as inputs of the model, while permeate flux and Specific Thermal Energy Consumption (STEC) were chosen as responses. The prediction abilities of both RSM and ANN models were compared with further experimental data by using the Analysis of Variance (ANOVA) and the Root Mean Squared Error (RMSE). The results show that the ANN model is able to predict in a more precise way the behaviour of the module for the whole range of input variables. Thus, ANN model was used to find the optimal operating conditions, for the module operating at feed water salinity of 70 and $105 \mathrm{~g} / \mathrm{L}$, concentrations that can be reached when desalting RO brines.
\end{abstract}

Keywords: Permeate-gap Membrane Distillation, Response Surface Methodology, Artificial Neural Network, Multiobjective Optimization, Brine Treatment.

\section{Introduction}

Due to the high tolerance of MD systems to high salinity feeds, one of the possible industrial applications of this technology consists on desalting seawater

\footnotetext{
* Corresponding author.

Email address: guillermo.zaragoza@psa.es (Guillermo Zaragoza)
} 
$\mathrm{RO}$ brines. Integrating MD technology in RO plants could be an essential factor 5 to obtain efficient desalination lines in terms of recovery [1-4]. However, the uncertainty associated with the performance of MD technology at large scale has prevented the development of this kind of applications so far [5] [ Therefore, investigating the performance of large scale MD systems, under the operating conditions imposed by RO brine, is required for assessing the energy efficiency 10 which is one of the main barriers of the MD technology [6]. In this context, the development of accurate theoretical (first principles-based) or empirical models, to predict the performance of MD processes is fundamental. Models not only allow designers to simulate and analyze MD systems under the required operating conditions $9 \sqrt{12}$, but can also be used for developing real time optimization

15 strategies [13, 14, or to develop optimization algorithms aimed at obtaining optimal designs of the application at hand [15].

The construction of first principles based models requires a total knowledge of the process to be modeled, and it is usually a laborious task. On the contrary, this knowledge is not as necessary to elaborate empirical models, but in this ${ }_{20}$ case a good selection of the dependent and independent variables, and a good design of experiments are needed. Additionally, in the case of MD systems, the difficulty in constructing theoretical models is greater as the different internal design of each module influences its performance. So, internal modifications of this theoretical models have to be done to adapt them to the different module 25 designs, which in many case is non-disclosed information. For that reason, the use of empirical models is a good option to obtain a mathematical expression in a relatively fast and simple way. Two of the most common empirical models used in the field of membrane sciences to visualize the operational space and to understand the system behaviour are RSM and ANN [16, 17]. These models, 30 also known as black blox models, are able to fit both linear and nonlinear multivariable problems. It should be remarked that these kind of empirical models cannot been used to extrapolate the results to other systems, and they are only valid for the range of operation in which they have been calculated.

RSM is a statistical method extensively used for characterizing membrane

35 distillation systems. This methodology is an efficient modeling tool providing quadratic functions to fit responses in linear or smooth nonlinear processes. As can be seen in Tab. 1. most works presented until now in the literature use RSM in order to optimize MD systems in terms of two of the most important parameters in this technology: permeate production and thermal energy efficiency.

40 However, not all works treat these two parameters in a simultaneous way [9, 1824]. In addition, in most papers the feed water salt concentration, one of the most important paremeters influencing the performance of MD systems, is not taken into account as an input of the model [9, 12, 18, 19, 22, 23, 25, 26].

ANN is an emerging modeling tool in the field of MD systems. The main 45 advantage of this methodology is that it is able to fit almost all nonlinear processes. Besides, the way in which the model is built allows retraining the model with further experimental data for improving predictions. Tab. 2 summarizes the proposals made up to now in the literature for modeling MD systems by means of ANN based models. As can be seen, almost all the works use ANN for 
50 characterizing only the permeate production of a MD unit [10, 11, 14, 27, 28], and only Shibazian and Alibabaei [29] consider also the thermal energy. Furthermore, the feed water salt concentration is only considered by Cao et al. [27] and Tavakolmoghadam and Safavi [28].

55 The goal of this work is to develop empirical models able to predict, in a precise way, the performance of a commercial-scale PGMD module for desalting $\mathrm{RO}$ brines. For this purpose, three main objectives are developed: i) obtaining empirical forecasting models based on RSM and ANN, under the required operating conditions, ii) comparing the prediction abilities of the two modeling

60 approaches, and iii) finding the optimal operating conditions of this module for two of the salinity concentrations that can be reached when desalting RO brines, 70 and $105 \mathrm{~g} / \mathrm{L}$. Compared to most modeling approaches presented until now in the literature (see Tabs. 1 and 2), in this work, both the permeate production and the thermal energy consumption were selected as predicted per-

65 formance parameters. In addition, apart from the typical independent variables considered in this technology (condenser inlet temperature, evaporator inlet temperature, and feed flow rate), the feed water salt concentration (35-140 g/L) has been used as an input, in order to visualize the effect of this parameter in the responses. It should be pointed out that most of the studies presented in the

70 literature use bench-scale modules, whereas this study has been performed using a commercial-scale module, which can be very relevant to commercial purposes. 


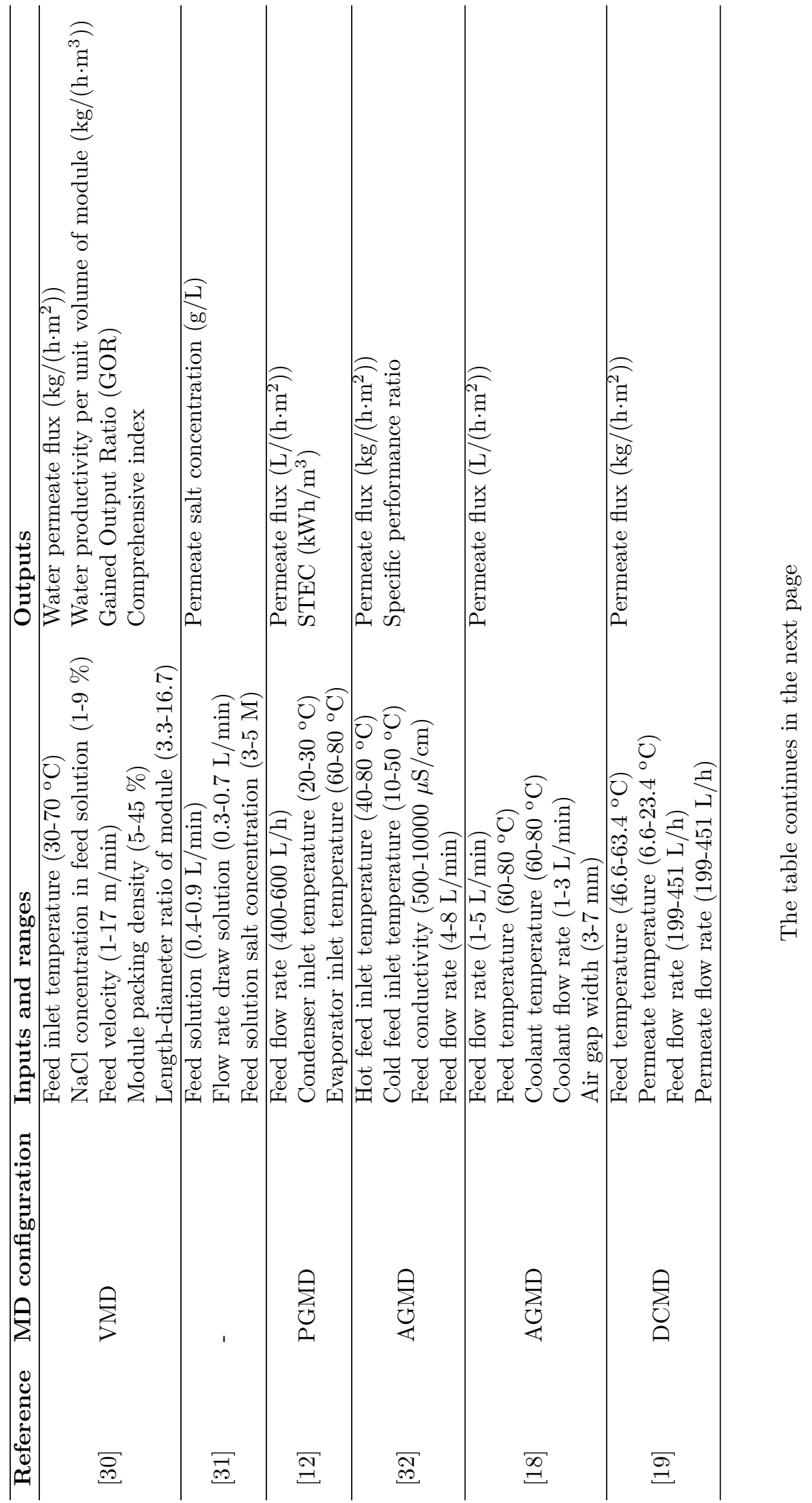




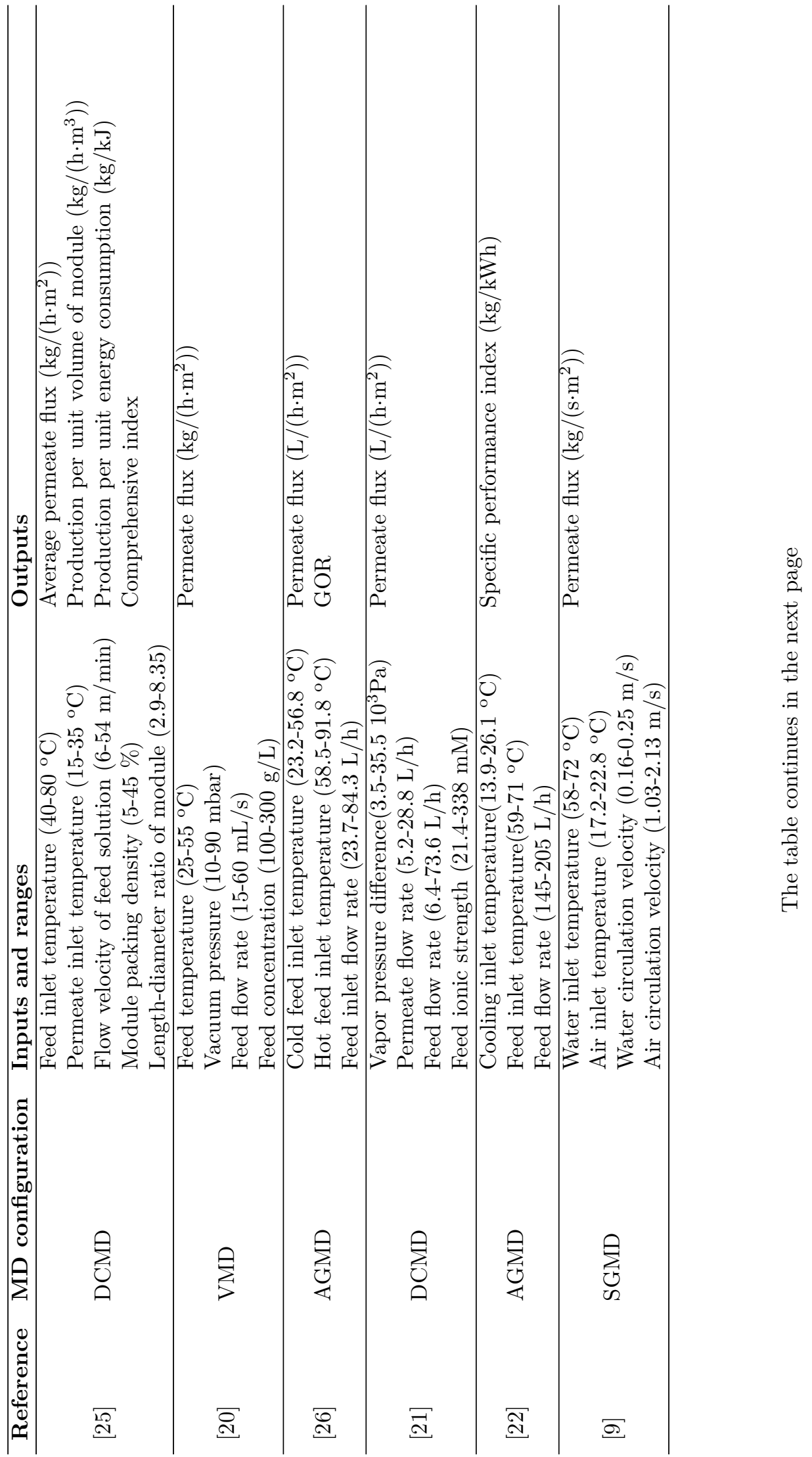




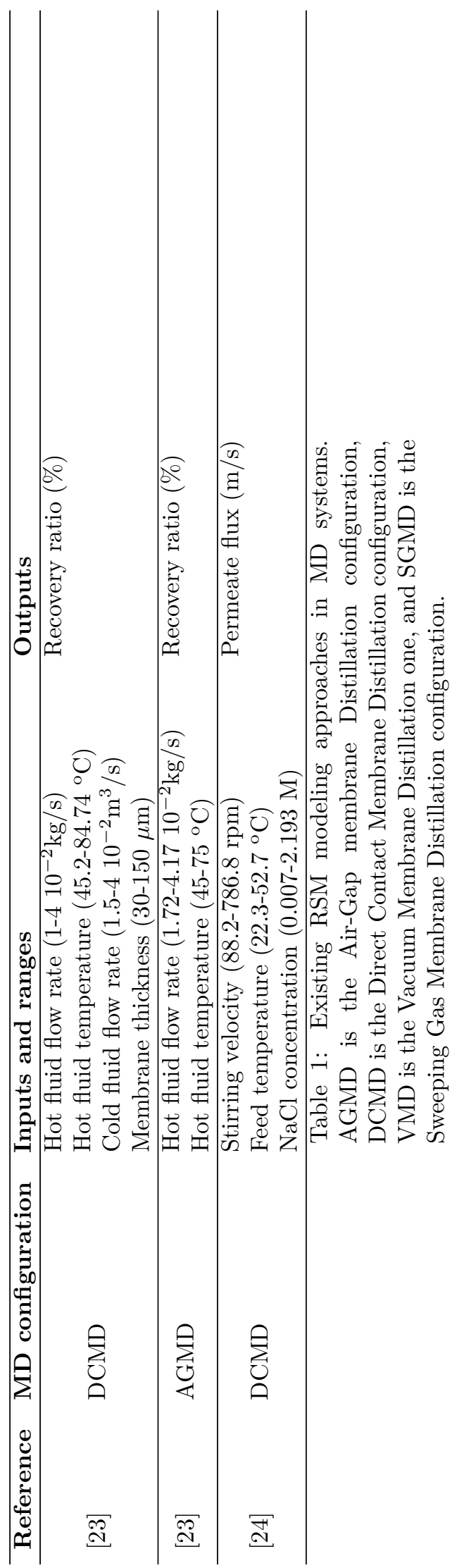




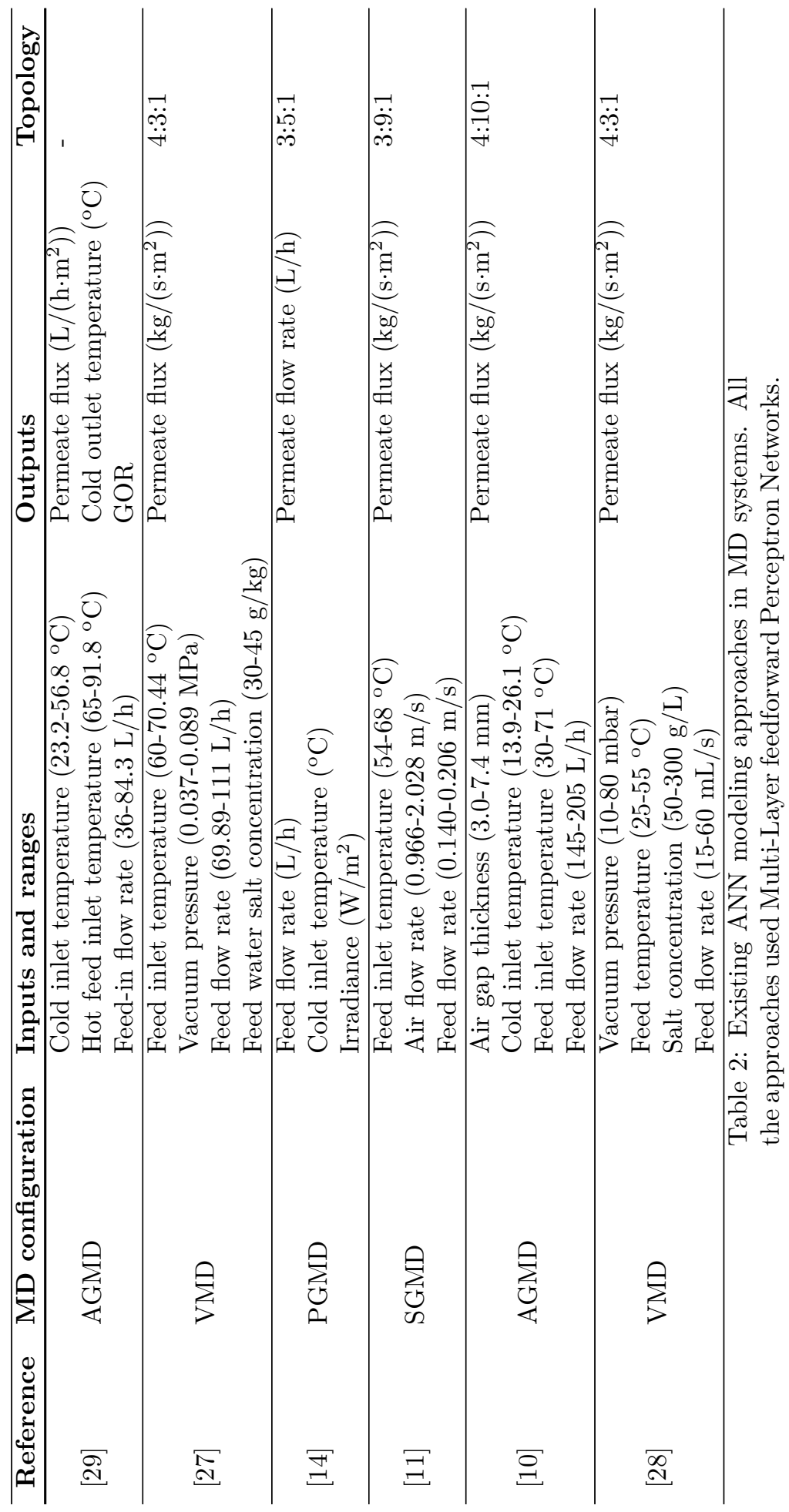




\section{Methodology}

\subsection{Test-bed facility}

In this study, a spiral wound MD commercial module called Oryx 150 was 75 evaluated (see Fig. 1 b). The module was designed by the Fraunhofer Institute for Solar Energy systems and is marketed by the company Solar Spring (Freiburg, Germany). It had a Permeate Gap Membrane Distillation (PGMD) configuration. The location of the different channels of the module was placed to minimize heat losses to the environment. All inlets and outlets were located

so at the top of the module. The permeate outlet was located on the outer perimeter of the coil to facilitate the recovery of sensible heat from the permeate. This module had a length, a height and a channel width of $7 \mathrm{~m}, 0.7 \mathrm{~m}$ and $3.2 \mathrm{~mm}$ respectively. The membrane surface area was $10 \mathrm{~m}^{2}$. The membrane used in the module was a commercial membrane of W. L. Gore Associates.

85 The membrane was constituted by an active Polytetrafluoroethylene (PTFE) layer with a nominal pore size of $0.2 \mu \mathrm{m}$, a thickness of $70 \mu \mathrm{m}$ and a porosity of $80 \%$ and a support of Polypropylene (PP) with a thickness of $280 \mu \mathrm{m}$ and a porosity of $50 \%$. The spacers were made of Low-Density Polyethylene (LDPE) and the condensation foil was made of Ethylene Tetrafluoroethylene (ETFE).

90 The permeate gap was created by a PP spacer of $1 \mathrm{~mm}$. The Oryx 150 module was integrated into a structure that was formed by a feed tank $(475 \mathrm{~L})$, a filter of $300 \mu \mathrm{m}$ placed after the outlet of the feed tank and before the inlet of the MD module, the pump to circulate the feed solution, a deaerator and the heat exchanger. Four PT100 temperature sensors were placed directly at the 95 inlet of the evaporator and condensation channels and at the outlets of them (see Fig. 2). The fifth temperature sensor was located at the inlet of the heat exchanger on the side of the heating fluid (see Fig. 2). The volumetric flow rate (F in Fig. 2) was measured with a flow meter placed before the inlet of the condenser channel. A pressure sensor (WIKA) was located at the inlet of the 100 condenser channel to avoid overpressure. The permeate was measured with a weight (W in Fig. 2), using a tank to collect the permeate, and then, returning it to the feed tank. All the temperature and pressure measurements were monitored and registered by a Supervisory Control And Data Acquisition (SCADA) system connected through a Programmable Logic Controller (PLC).

105 The MD module was tested in the Solar Membrane Distillation (SMD) pilot facility of Plataforma Solar de Almería (PSA, www.psa.es) (see Fig. 1 -a). In this facility, the module was connected to a solar field through a heat exchanger. The solar field was formed by 10 flat plate collector (Solaris CP1 Nova, Solaris, Spain) divided into two files with 5 collectors each one. The nominal thermal 110 power supplied was $7 \mathrm{~kW}_{\text {th }}$ at a temperature of $90{ }^{\circ} \mathrm{C}$. The heat rate supplied to the heat exchanger was controlled by means of the feedback control structure presented in [33].

The operation of the MD system consisted of pumping the cold feed solution to the condenser inlet. The low temperature of the feed solution helped

115 the condensation of the permeate. The circulation of the feed solution along the condensation channel allowed preheating the solution thanks to the latent 

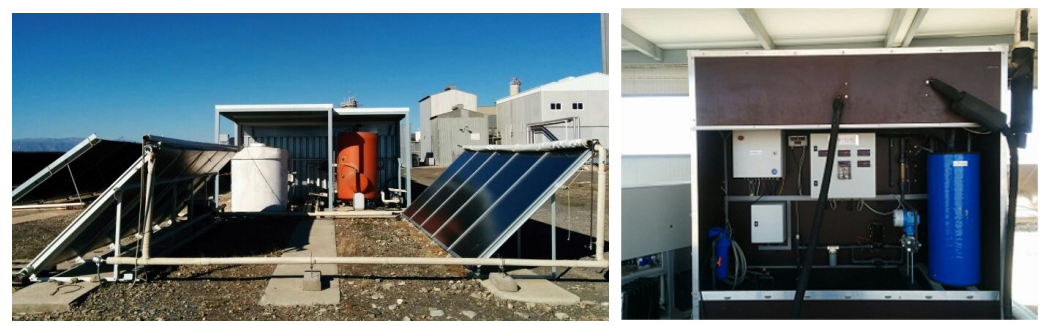

(a) SMD facility. (b) Solar Spring pilot module.

Figure 1: Test-bed facility at Plataforma Solar de Almería (PSA).

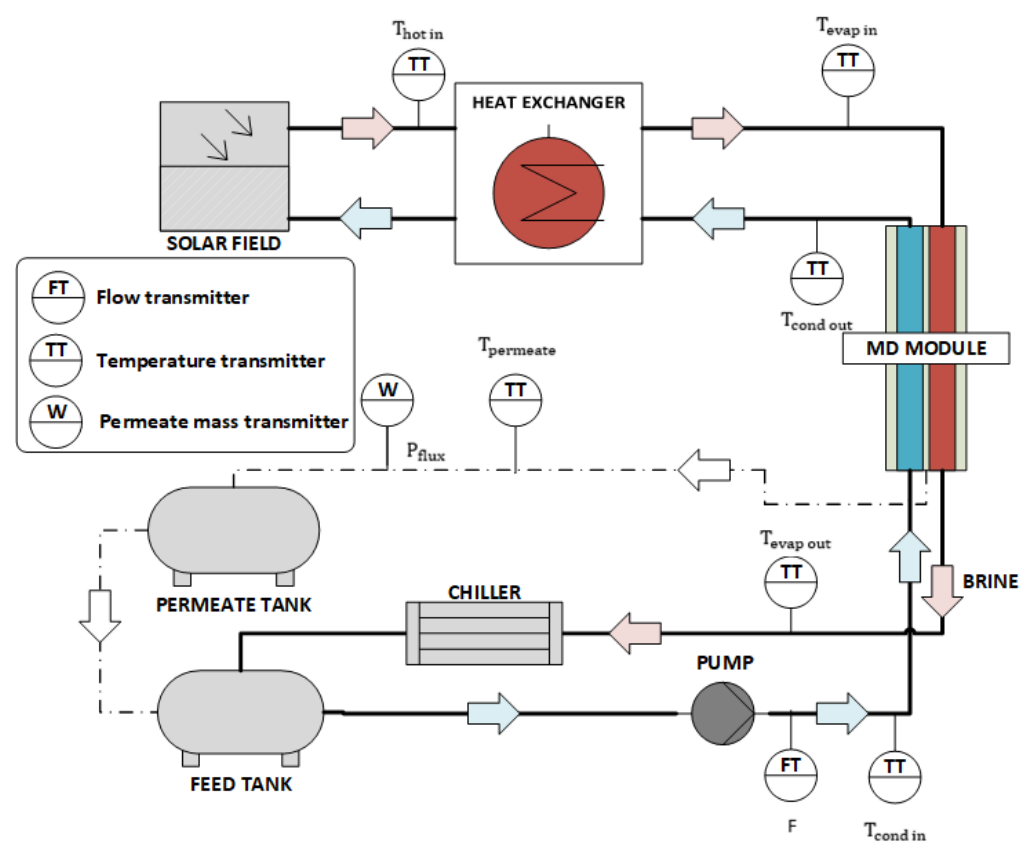

Figure 2: Schematic diagram of the test-bed facility.

heat of condensation and to the sensible heat that crossed the membrane. After leaving the condensation channel, the solution passed to the deaerator to eliminate the non-condensable gases from the feed solution and later it was cir120 culated towards the inlet of the heat exchanger. Afterwards, the hot feed went into the evaporator channel and circulated countercurrent with respect to the circulation in the condensation channel. As the feed circulated along the evaporator channel, the vapour passed through the pores of the membrane driven by the vapour pressure difference created on both sides of the membrane due to the temperature difference. The concentrated feed solution (brine) left the 
module through the outlet of the evaporator channel and was poured into the feed tank for recirculation. Since the brine had a temperature above that of the feed solution, it was cooled down with a chiller.

\subsection{Thermal energy performance metric}

The thermal efficiency of the distillation process can be evaluated by means of several metrics, being the Specific Thermal Energy Consumption (STEC), the one adopted in this work, one of the most employed [12, 34] 36]. This metric provides the thermal energy required per volume unit of distillate, and it can be calculated as follows:

$$
\operatorname{STEC}\left(\mathrm{kWh} / \mathrm{m}^{3}\right)=\frac{\mathrm{F} \cdot \rho_{\text {feed }} \cdot c_{p} \cdot\left(\mathrm{T}_{\text {evap in }}-\mathrm{T}_{\text {cond out }}\right)}{c \cdot \mathrm{D}},
$$

where $c$ is a conversion factor $\left(3.6 \cdot 10^{6} \mathrm{~s} \cdot \mathrm{W} /(\mathrm{h} \cdot \mathrm{kW})\right), \rho_{\text {feed }}$ is the feed water density $\left(\mathrm{kg} / \mathrm{m}^{3}\right), c_{p}$ is the heat water capacity $\left(\mathrm{J} /\left(\mathrm{kg} \cdot{ }^{\circ} \mathrm{C}\right)\right)$, D is the permeate flow rate $(\mathrm{L} / \mathrm{h})$, and the rest of variables are according to Fig. 2 .

\subsection{Response Surface Methodology (RSM)}

RSM is a set of mathematical and statistical techniques based on the fitting of empirical models to the experimental data obtained through an experimental design. The RSM procedure consists of the development of a linear or quadratic polynomial function that adjusts the response (permeate production, energy efficiency and so on) depending on the operating conditions (temperatures, flow rates and so on). Therefore, polynomial functions are used to describe the studied system and consequently, to explore (model and displace) the experimental conditions up to their optimization to achieve the best performance of the system 37 .

The development of a RSM has several steps: (i) selection of the main variables that exert the highest effect on the system through the screening studies and the delimitation of the experimental region, in accordance with the goal of the study and the experience of the researcher; (ii) choice of an experimental design that defines which experiments should be carried out in the experimental region and conduction of the experiments according to the selected experimental matrix; (iii) mathematical-statistical treatment of the experimental data by adjusting a polynomial function (see Eq. 2); (iv) evaluation of the validity of the model.

$$
y=\beta_{0}+\sum_{i=1}^{k} \beta_{i} \cdot x_{i}+\sum_{i=1}^{k} \beta_{i i} \cdot x_{i}^{2}+\sum_{1 \leq i \leq j}^{k} \beta_{i j} \cdot x_{i} \cdot x_{j},
$$

where $k$ is the number of variables, $\beta_{0}$ is the offset term coefficient, $\beta_{i}$ represents the coefficients of the linear effects, $x_{i}$ and $x_{j}$ represents the variables, ${ }_{145} \beta_{i j}$ represents the coefficients of the interaction of effects, and $\beta_{i i}$ represents the coefficients of the quadratic parameters. To estimate the coefficients of the equation, the experimental design must ensure that all the studied variables 
are carried out for at least three levels of each variable. Among the most used second order design are the three-level factorial design, the Box-Behnken design and the central composite design. These designs differ from each other in their selection of experimental points, number of levels for the variables and number of executions. In particular, central composite design is a fractional factorial or factorial design with extended central points with a group of axial points also called star points. So, for example, to optimize a process with three variables $155(k=3)$, the first block is a factorial $2^{3}$, the second block is a set of $2 \times 3$ tests and the third blocks are repetitions in the center [38. There are three types of central composite design, specifically, circumscribed, inscribed and face-centered central composite. In the last one, the star points are the center of each face of the vector space, so this variety requires only three levels of for each factor. After the experimental plan proposed by the design has been carried out and the values of the responses have been obtained for each experimental point, it is necessary to evaluate the quality of the adjusted model by applying the ANOVA [39. With the ANOVA, the variation due to the treatment (change in the combination of the levels of the variables) is compared with the variation due to the 165 random errors inherent in the measurements of the generated responses. From this comparison, it is possible to evaluate the significance of the regression used to predict the answer.

\subsection{Artificial Neural Network (ANN)}

An ANN is also a mathematical model which is composed by simple interconnected elements, that process information in response to external inputs, trying to imitate the behaviour of biological neural networks. These simple elements, called neurons, are computational processors in which three main operations (see Fig. 3) are carried out [40, 41]:

1. The $n$-element input vector $\left(\mathrm{z}_{1}, \mathrm{z}_{2}, \ldots \mathrm{z}_{n}\right)$ is multiplied by weights $\left(\mathrm{w}_{1,1}\right.$, $\left.\mathrm{w}_{1,2}, \ldots \mathrm{w}_{1, n}\right)$.

2. In the summing junction, the weighted inputs are added together with the bias vector $b$, obtaining the argument $a$ :

$$
a=\mathrm{z}_{1} \cdot \mathrm{w}_{1,1}+\mathrm{z}_{2} \cdot \mathrm{w}_{1,2}+\ldots+\mathrm{z}_{n} \cdot \mathrm{w}_{1, n}+b .
$$

3. Finally, the argument $a$ is converted into a scalar value $O u t$ by means of the transfer function $f$ (see Fig. 3):

$$
\text { Out }=f(\mathbf{z W}+b) .
$$

In the transfer function block ( $f$ in Fig. 3), several functions can be employed, being the linear (purelin) and the log-sigmoid (logsig) transfer functions two of the most adopted [40, 41. Thus, the outputs of neurons calculated by these transfer functions can be expressed as:

$$
\text { Purelin : Out }=f(a)=a,
$$




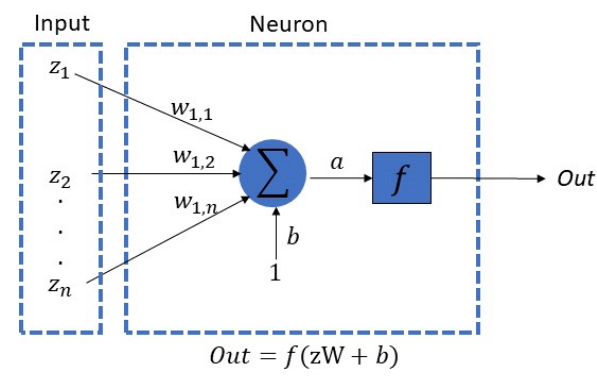

Figure 3: Schematic diagram of an artificial neuron.

$$
\text { Logsig : Out }=f(a)=\frac{1}{1+e^{a}} .
$$

The form in which neurons are grouped and connected is known as topol-

ogy or architecture of the neural network. In general, neurons are grouped in different layers such as hidden and output layers. Moreover, the inputs can be treated as an additional layer. Between the different kinds of architectures, one of the most used to perform function fitting is the Multi-Layer feedforward Perceptron (MLP) [42]. In this architecture, the number of inputs and outputs of the network is defined according to the number of input and output variables of the system to be modeled. On the other hand, the optimal selection of the number of layers, and the number of neurons required in each layer, is still an active research area and it is usually obtained by trial and error. In practice, most neural networks have only two or three hidden layers [42].

Once the architecture of the network is chosen, the weights and biases are adjusted by mean of a training algorithm. Back Propagation (BP) algorithm is the most commonly employed for training MLP networks [10, 11, 17, 42]. This algorithm tries to minimize a performance function by iteratively adjusting network weights and biases. The index used as performance function in this work is the Root Mean Square Error (RMSE):

$$
\mathrm{RMSE}=\sqrt{\frac{\sum_{i=1}^{M} \sum_{j=1}^{N}\left(Y_{i, j}-\hat{Y}_{i, j}\right)^{2}}{M \cdot N}},
$$

where $M$ is the number of network outputs, $N$ is the number of data used for training, and $Y_{i, j}$ and $\hat{Y}_{i, j}$ is the experimental and predicted response respectively. Thus, in each iteration BP algorithm modifies weights and biases in the direction in which RMSE decreases. One iteration of this algorithm is given by [42]:

$$
\boldsymbol{\lambda}_{k+1}=\boldsymbol{\lambda}_{k}-\delta \boldsymbol{\Delta}_{k},
$$

where $\boldsymbol{\lambda}_{k}$ is a vector containing current network weights and biases, $\delta$ is the learning rate, $\boldsymbol{\Delta}_{k}$ is the current gradient of RMSE function, and $\mathrm{k}$ being the iteration number. 


\subsection{Multi-objective optimization}

The space of solutions of the RSM model can be easily explored by a con-

205

3.1. Response Surface Methodology based model

225 specific thermal energy consumption (STEC) and permeate flux $\left(\mathrm{P}_{\text {flux }}\right)$, as a function of the main parameters that affect the performance in this technology, which are summarized in Tab. 3 Notice that the variables have been selected according to the allowed operational limits of the module [12], since the objective is to perform a realistic study in commercial-scale. After choosing the variables, , the Design of the Experiment (DoE) was carried out with Statgraphics centurion, a highly specific multivariate analysis package. The chosen design to obtain the experimental campaign was the Face-centered Central Composite $(\mathrm{CCF})$ design which required three levels of each of the variables. The data 235 proposed by the CCF design for modeling are presented in Appendix A. 


\begin{tabular}{ccccc}
\hline \multirow{2}{*}{ Terms } & \multicolumn{2}{c}{$\mathrm{P}_{\text {flux }}\left(\mathrm{L} /\left(\mathrm{h} \cdot \mathrm{m}^{2}\right)\right)$} & \multicolumn{2}{c}{ STEC $\left(\mathrm{kWh} / \mathrm{m}^{3}\right)$} \\
& Coefficient & P-value & Coefficient & P-value \\
\hline $\mathrm{T}_{\text {evap }}$ & 0.039820 & 0.0000 & -75.525 & 0.0006 \\
$\mathrm{~T}_{\text {cond }}$ & -0.000171 & 0.0000 & 105.672 & 0.0505 \\
$\mathrm{~F}$ & 0.002683 & 0.0000 & -6.079 & 0.1223 \\
$\mathrm{~S}$ & -0.010709 & 0.0000 & 26.804 & 0.0000 \\
$\mathrm{~T}_{\text {evap }} 2$ & -0.000065 & 0.7800 & 0.613 & 0.5504 \\
$\mathrm{~T}_{\text {evap }} \cdot \mathrm{T}_{\text {cond }}$ & -0.000063 & 0.7383 & -1.365 & 0.1147 \\
$\mathrm{~T}_{\text {evap }} \cdot \mathrm{F}$ & 0.000062 & 0.0000 & 0.059 & 0.1651 \\
$\mathrm{~T}_{\text {evap }} \cdot \mathrm{S}$ & -0.000208 & 0.0000 & -0.273 & 0.0042 \\
$\mathrm{~T}_{\text {cond }} 2$ & -0.000181 & 0.8463 & 0.613 & 0.8804 \\
$\mathrm{~T}_{\text {cond }} \cdot \mathrm{F}$ & 0.000006 & 0.7383 & -0.113 & 0.1838 \\
$\mathrm{~T}_{\text {cond }} \cdot \mathrm{S}$ & -0.000107 & 0.0104 & 0.368 & 0.0336 \\
$\mathrm{~F}^{2}$ & -0.000004 & 0.1374 & 0.005 & 0.5966 \\
$\mathrm{~F} \cdot \mathrm{S}$ & -0.000009 & 0.0002 & -0.014 & 0.0758 \\
$\mathrm{~S}^{2}$ & 0.000132 & 0.0000 & -0.024 & 0.5127 \\
\hline
\end{tabular}

Table 4: Values of the regression coefficients and their statistical significance.

After carrying out the experimental campaign and introducing the experimental values of the responses of interest, the experimental design was analyzed. The ANOVA analysis was used to verify if the regression equations were statistically valid. The statistical parameters used to evaluate the goodness of the fit was the p-value, the coefficient of determination $\left(\mathrm{R}^{2}\right)$ and the adjusted coefficient of determination (adjusted- $\mathrm{R}^{2}$ ). Specifically, the $\mathrm{p}$-value was used to determine which terms of the equation were statistically significant. For that, the p-value was compared with the level of significance to decide which terms were excluded from the final model. A value of 0.05 was used for the level of significance, meaning that if the p-value was lower than 0.05 , the coefficient was significantly different from zero with a confidence level of $95 \%$. Therefore, the coefficients with a p-value higher than 0.05 were not included in the final equations. Tab. 4 shows the p-values of the coefficients for both responses (STEC and $\left.\mathrm{P}_{\text {flux }}\right)$. Thus $\mathrm{T}_{\text {evap }}, \mathrm{T}_{\text {cond }}, \mathrm{F}, \mathrm{S}, \mathrm{T}_{\text {evap }} \cdot \mathrm{F}, \mathrm{T}_{\text {evap }} \cdot \mathrm{S}, \mathrm{T}_{\text {cond }} \cdot \mathrm{S}, \mathrm{F} \cdot \mathrm{S}$ and $\mathrm{S}^{2}$ were 250 significant for Pflux while for STEC, only $T_{\text {evap }}, S$ and $T_{\text {evap }} \cdot S$ were statistically significant. Non-significant terms were removed from the model to obtain the simplified equations for both Pflux and STEC:

$$
\begin{aligned}
\mathrm{P}_{\text {flux }} & =-0.8868+0.0291 \cdot \mathrm{T}_{\text {evap }}-0.0104 \cdot \mathrm{T}_{\text {cond }}-0.0008 \cdot \mathrm{F}-0.0087 \cdot \mathrm{S} \\
& +0.000061 \cdot \mathrm{T}_{\text {evap }} \cdot \mathrm{F}-0.0002 \cdot \mathrm{T}_{\text {evap }} \cdot \mathrm{S}-0.0001 \cdot \mathrm{T}_{\text {cond }} \cdot \mathrm{S} \\
& -0.000009 \cdot \mathrm{F} \cdot \mathrm{S}+0.0001 \cdot \mathrm{S}^{2} \\
& \mathrm{STEC}=-317.712+5.874 \cdot \mathrm{T}_{\text {evap }}+24.296 \cdot \mathrm{S}-0.273 \cdot \mathrm{T}_{\text {evap }} \cdot \mathrm{S}
\end{aligned}
$$

The simplified equations were also subjected to an analysis of variance. Tab. 5 shows the values of the statistics for the simplified models for $\mathrm{P}_{\text {flux }}$ and 


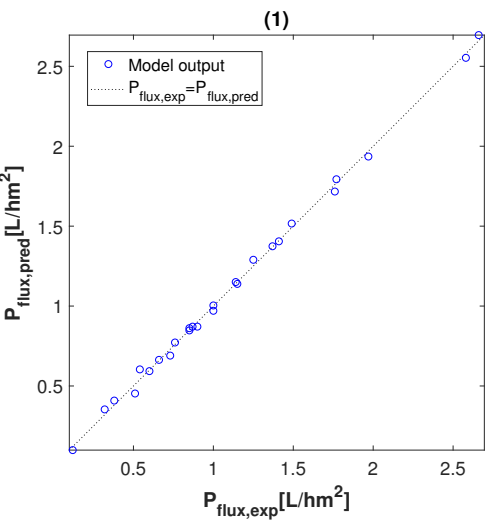

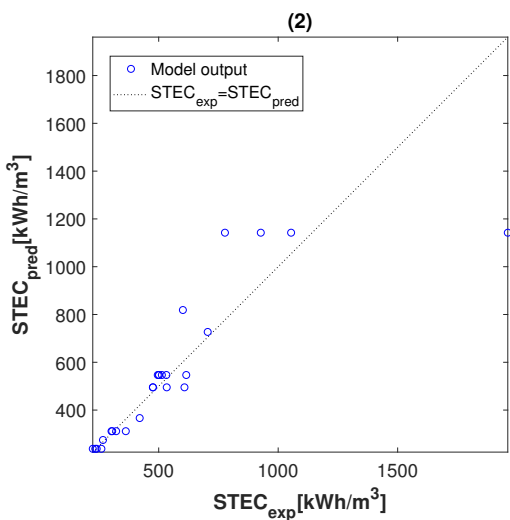

Figure 4: Comparison between predicted values by RSM model $\left(\mathrm{STEC}_{\text {pred }}\right.$ and $\left.\mathrm{P}_{\text {flux,pred }}\right)$ and experimental data $\left(\mathrm{STEC}_{\exp }\right.$ and $\left.\mathrm{P}_{\text {flux,exp }}\right)$.

\begin{tabular}{cccc}
\hline Statistical estimator & Condition for a good fit & $\mathrm{P}_{\text {flux }}$ & STEC \\
\hline $\mathrm{p}$-value & $\leq 0.05$ & $\leq 0.01$ & $\leq 0.02$ \\
$\mathrm{R}^{2}$ & closed to 1 & 0.998 & 0.704 \\
adjusted- $\mathrm{R}^{2}$ & in agreement with $\mathrm{R}^{2}$ & 0.996 & 0.664 \\
\hline
\end{tabular}

Table 5: Goodness of the adjustment of the simplified models of $\mathrm{P}_{\text {flux }}$ and STEC

\subsection{Neural Network based model}

The neural network based model was developed considering as inputs $\mathrm{S}$, $\mathrm{T}_{\text {cond }}, \mathrm{T}_{\text {evap }}$ and $\mathrm{F}$ (see Tab, 3), and as outputs $\mathrm{P}_{\text {flux }}$ and STEC. In this case, the

data used in the RSM method were complemented with more samples. It should be remarked that, although DoE ensures data well distributed throughout all the input data range, the ANN model, which is exclusively data-based, can present abrupt nonlinearities in the responses if the amount of data is not large enough, and if the data set is not well distributed. This fact can be especially significant 
275 when the range of the input data is large, and some of these parameters have a clear nonlinear influence on the responses, as is the case of feed water salt concentration in this study. Thus, Appendix A shows all the experimental data. Besides, it should be commented that, as in the case of experimental data used in RSM model, four measurements were taken for each experimental point.

The experimental data set was divided in 3 subsets: i) training subset $(75 \%$ of samples), ii) validation subset (20\% of samples), and iii) test subset ( $5 \%$ of samples). Moreover, in order to avoid overfitting during the training process, both the input and output variables were normalized in the range 0.1-0.9 by means of the following expression [10]:

$$
y_{n}=(1-U-L) \cdot \frac{y_{k}-y_{\min }}{y_{\max }-y_{\min }}+L,
$$

where $y_{n}$ is the normalized sample, $y_{k}$ is the actual sample, $y_{\max }$ and $y_{\min }$ are the maximum and minimum value of the variable to be normalized, and $U$ and $L$ are the upper and lower bounds considered to define the output network range $(U=L=0.1)$.



Figure 5: Schematic diagram of the optimal network architecture. $\mathrm{x}_{1}, \mathrm{x}_{2}, \mathrm{x}_{3}$ and $\mathrm{x}_{4}$ are $\mathrm{S}$, $\mathrm{T}_{\text {cond }}, \mathrm{T}_{\text {evap }}$ and $\mathrm{F}$, while $\hat{\mathrm{Y}}_{1}$ and $\hat{\mathrm{Y}}_{2}$ are $\mathrm{P}_{\text {flux }}$ and STEC.

The training process was accomplished in the Neural Network Toolbox of MATLAB, using the Lavenberg-Marquardt BP algorithm [40]. Several ANN architectures were tested varying the number of hidden layers between 1-3 and the number of neurons in each layer between 1-10. The transfer function adopted in the hidden layers was the logsig, whereas the one employed in the output layer was the purelin. The optimal architecture was selected according to the performance function (RMSE). 


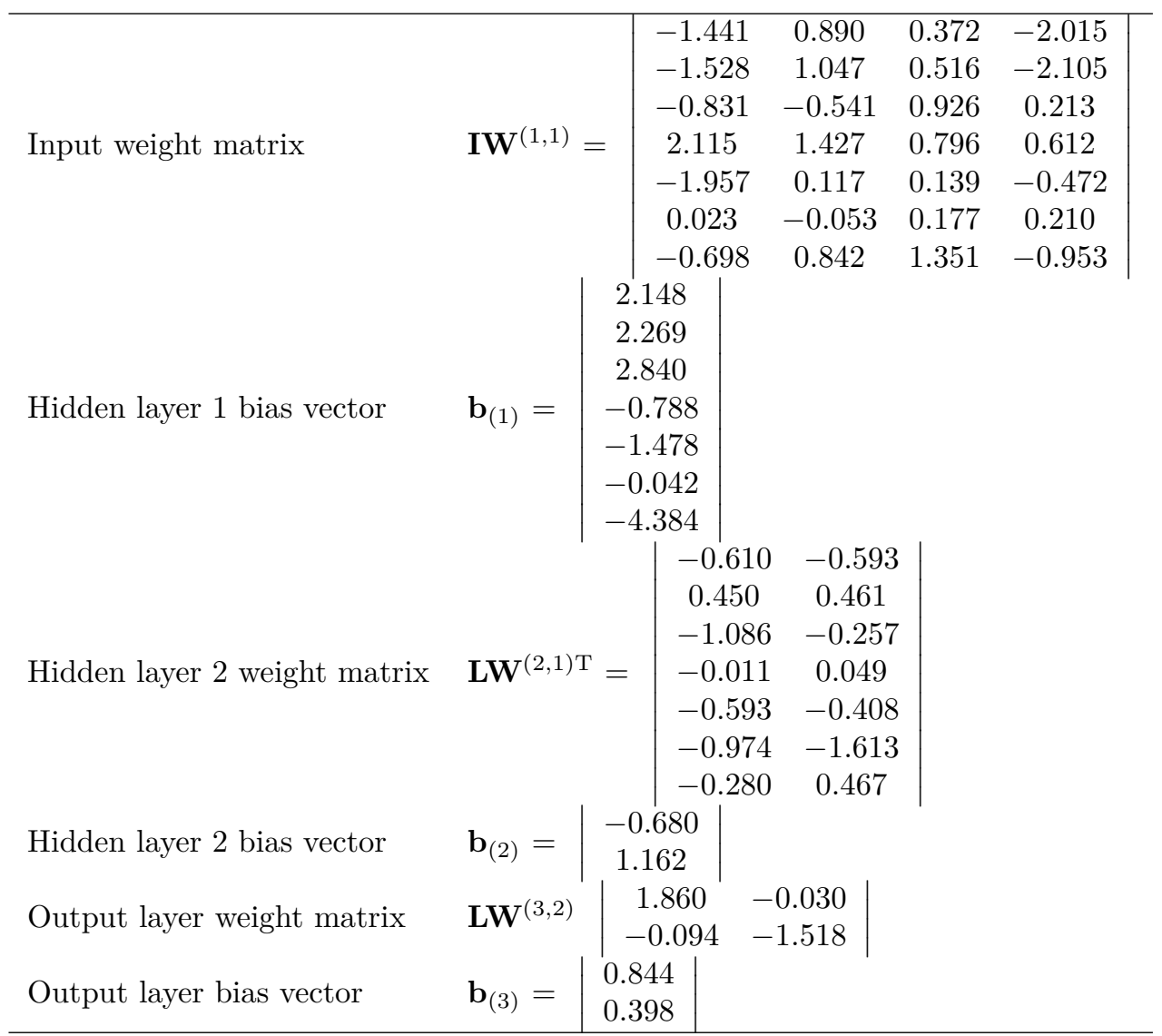

Table 6: Optimal network weights and bias.

The optimal ANN model (see Fig. 5) is composed by 4 inputs, two hidden layers containing 7 and 2 neurons respectively, and two outputs. This feedforward neural network topology can be described as MLP (4:7:2:2). Notice that the training process was iteratively performed (as was metioned in Section 2.4) until reaching a RMSE sufficiently small, according to the imposed goal for the training subset (RMSE $\leq 5 \cdot 10^{-4}$, normalized value according to Eq. 11). In the optimal network case, the training process was stopped after 13 iterations obtaining a $\mathrm{RMSE}=2 \cdot 61 \cdot 10^{-4}$ for the training data subset, while the RMSE of the validation and test subsets was lower than $1 \cdot 10^{-3}$. Tab. 6 summarizes the optimal values of network weights and bias in a matrix-vector format. The ANN model can be expressed as:

$$
\hat{\mathbf{Y}}=\Phi^{(3)}\left(\mathbf{L} \mathbf{W}^{(3,2)} \Phi^{(2)}\left(\mathbf{L} \mathbf{W}^{(2,1)} \Phi^{(1)}\left(\mathbf{I} \mathbf{W}^{(1,1)} \mathbf{x}+\mathbf{b}^{(1)}\right)+\mathbf{b}^{(2)}\right)+\mathbf{b}^{(3)}\right),
$$

where $\Phi^{(i)}$ is the transfer function correspondent to layer $i(i=1-3), \mathbf{L W}^{(2,1)}$ and $\mathbf{L} \mathbf{W}^{(3,2)}$ are the layer weight matrices, where the superscripts indicates the 
destination and source connections, $\mathbf{I} \mathbf{W}^{(1,1)}$ is the input weight matrix, $\mathbf{x}$ is the network input, and $\hat{Y}$ is the network output. It should be commented that the same notation has been employed in Tab. 6 and Fig. 5

The fit between the experimental data used in the training and validation processes, and the predicted values by the ANN model are shown in Fig. 6 Besides, Tab. 7 shows the analysis of variance (ANOVA) for these two subsets. As can be observed, the obtained p-values (lower than 0.05) and coefficients of determination (close to 1) evidence the good fit obtained by ANN model in both cases $\mathrm{P}_{\text {flux }}$ and STEC. Notice that in the next subsection more experimental data will be used to test the performance of the ANN model.
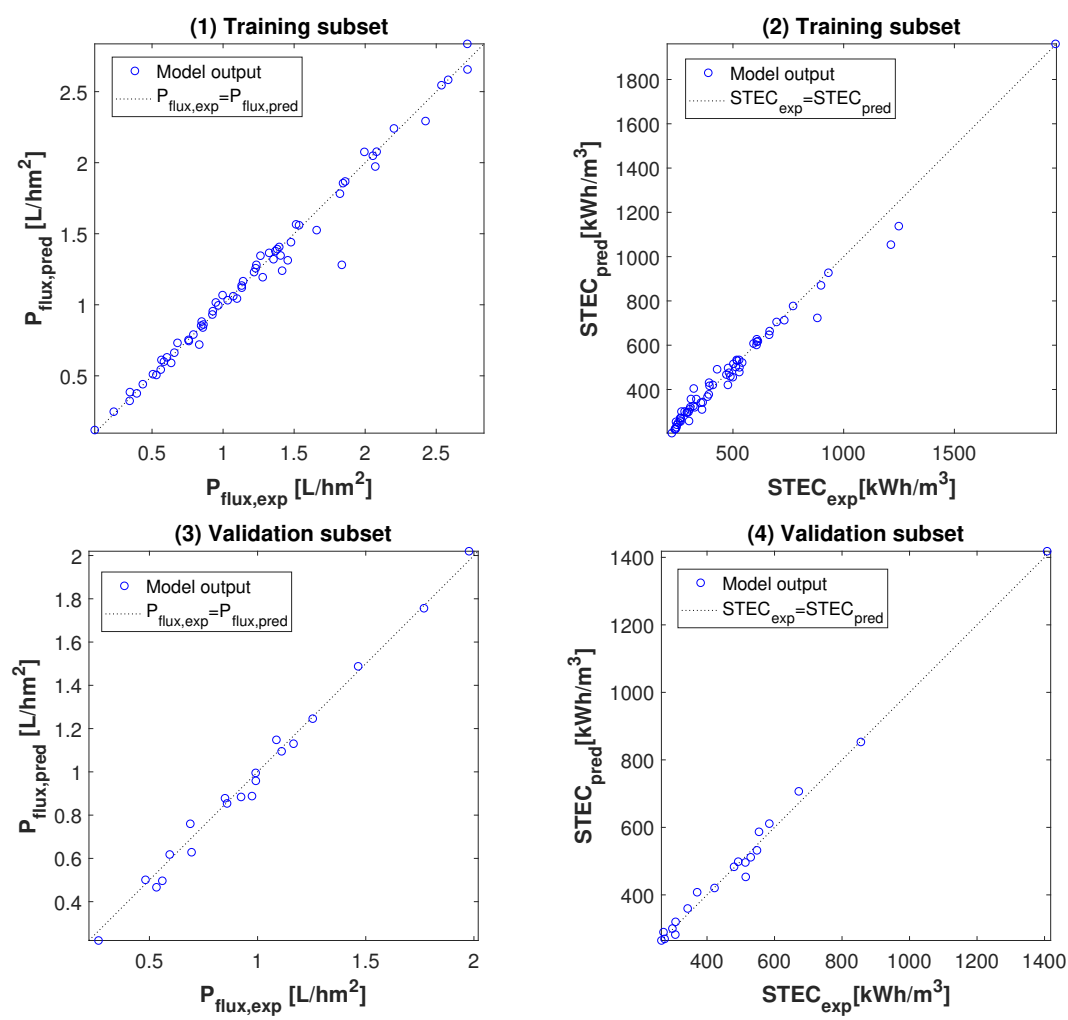

Figure 6: Comparison between predicted values by ANN model $\left(\mathrm{STEC}_{\text {pred }}\right.$ and $\mathrm{P}_{\text {flux,pred }}$ ) and experimental data $\left(\mathrm{STEC}_{\exp }\right.$ and $\left.\mathrm{P}_{\text {flux,exp }}\right)$. 


\begin{tabular}{ccccc}
\hline & \multicolumn{2}{c}{$\mathrm{P}_{\text {flux }}$} & \multicolumn{2}{c}{ STEC } \\
& Training & Validation & Training & Validation \\
\hline $\mathrm{p}^{\text {-value }}$ & $\leq 0.01$ & $\leq 0.01$ & $\leq 0.01$ & $\leq 0.01$ \\
$\mathrm{R}^{2}$ & 0.994 & 0.991 & 0.993 & 0.990 \\
adjusted- $\mathrm{R}^{2}$ & 0.993 & 0.990 & 0.992 & 0.989 \\
\hline
\end{tabular}

Table 7: Goodness of the adjustment of ANN model.

\subsection{Comparison between the prediction abilities of the two modeling approaches.}

In order to compare in the same conditions the prediction abilities of the RSM and ANN models, additional experimental data were employed (see Tab. 8). The comparison were performed based on the Root Mean Square Error (RMSE), the coefficient of determination $\left(\mathrm{R}^{2}\right)$ and the adjusted- $\mathrm{R}^{2}$.

\begin{tabular}{cccccc}
\hline $\mathrm{S}(\mathrm{g} / \mathrm{L})$ & $\mathrm{T}_{\text {cond }}\left({ }^{\circ} \mathrm{C}\right)$ & $\mathrm{T}_{\text {evap }}\left({ }^{\circ} \mathrm{C}\right)$ & $\mathrm{F}(\mathrm{L} / \mathrm{h})$ & $\mathrm{STEC}\left(\mathrm{kWh} / \mathrm{m}^{3}\right)$ & $\mathrm{P}_{\text {flux }}\left(\mathrm{L} /\left(\mathrm{h} \cdot \mathrm{m}^{3}\right)\right)$ \\
\hline 35 & 20 & 75 & 600 & 297.563 & 2.303 \\
35 & 25 & 75 & 400 & 246.323 & 1.568 \\
35 & 30 & 65 & 500 & 286.500 & 1.311 \\
60 & 20 & 65 & 600 & 506.388 & 1.141 \\
60 & 25 & 65 & 500 & 535.293 & 0.756 \\
60 & 30 & 65 & 400 & 453.794 & 0.580 \\
60 & 30 & 75 & 600 & 368.303 & 1.524 \\
140 & 20 & 75 & 500 & 499.528 & 1.054 \\
140 & 25 & 65 & 600 & 678.193 & 0.736 \\
140 & 30 & 65 & 400 & 1172.35 & 0.214 \\
\hline
\end{tabular}

Table 8: Additional experimental data used to compare the two modeling approaches.
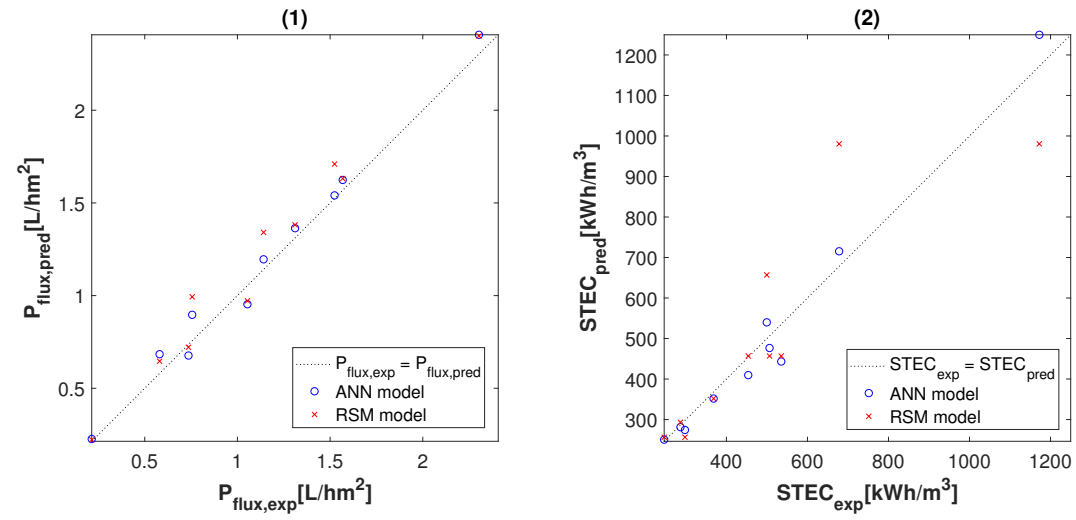

Figure 7: Comparison between predicted values of both models $\left(\mathrm{STEC}_{\text {pred }}\right.$ and $\left.\mathrm{P}_{\text {flux,pred }}\right)$ and experimental data $\left(\mathrm{STEC}_{\exp }\right.$ and $\left.\mathrm{P}_{\text {flux,exp }}\right)$. 


\begin{tabular}{ccccc}
\hline & \multicolumn{2}{c}{ RSM } & \multicolumn{2}{c}{ ANN } \\
& STEC & P flux $_{\text {fTEC }}$ & P flux $^{\text {ST }}$ \\
\hline RMSE & 85.70 & 0.10 & 27.01 & 0.06 \\
$\mathrm{R}^{2}$ & 0.770 & 0.985 & 0.982 & 0.988 \\
adjusted-R $^{2}$ & 0.742 & 0.984 & 0.981 & 0.987 \\
\hline
\end{tabular}

Table 9: Comparison of predictive abilities of RSM and ANN.

Fig. 7 shows the correlation between the additional experimental data and the predicted values, and Tab. 9 shows the performance metrics. On the one hand, in the case of the permeate flux $\left(\mathrm{P}_{\text {flux }}\right)$, the $\mathrm{R}^{2}$ and the adjusted- $\mathrm{R}^{2}$ values obtained with both models were similar (very close to 1 , see Fig. 7), whereas the obtained RMSE error was 0.06 and $0.10\left(\mathrm{~L} /\left(\mathrm{h} \cdot \mathrm{m}^{2}\right)\right)$ for the ANN and RSM model respectively, which evidences the good results obtained with both models. On the other hand, in the STEC case, the $\mathrm{R}^{2}$ and the adjusted- $\mathrm{R}^{2}$ values obtained with the ANN model were 0.982 and 0.981 respectively, whereas the ones obtained with the RSM model were 0.770 and 0.742 respectively. The RMSE of the ANN model was $27.01\left(\mathrm{kWh} / \mathrm{m}^{3}\right)$ while the RMSE of the RSM model was $85.70\left(\mathrm{kWh} / \mathrm{m}^{3}\right)$. It should be taken into account that the low grade of adjustment obtained by the RSM model in the STEC case can be explained for two main reasons: (1) the nonlinear behaviour of STEC with respect to feed water salt concentration, and (2) the simplified equation modeling STEC does not consider the influence of $\mathrm{T}_{\text {cond }}$ and $\mathrm{F}$ in the responses, hence it adds uncertainty to the model (see Eq. 10). Thus, it can be concluded that the ANN model is more suitable for predicting STEC, specially when working at high feed water salt concentration.

In addition to the comparison carried out previously, 3D response surfaces were displayed to observe the influence of the feed water salt concentration in both $\mathrm{P}_{\text {flux }}$ and STEC, and also to compare the surfaces provided by RSM and ANN models. It should be taken into account that the influence of the rest of input variables was studied in [12]. Thus, Figs. 8 and 9 show the 3D response surfaces for RSM and ANN models respectively.

On one hand, it can be observed in Fig. 8 1, 3 and 5, and in Fig. 951, 3 and 5 the influence of the feed water salt concentration and the other input variables $\left(\mathrm{T}_{\text {evap }}, \mathrm{T}_{\text {cond }}\right.$ and $\mathrm{F}$ ) in the $\mathrm{P}_{\text {flux }}$ predicted by the RSM and ANN models respectively. It can been seen that $\mathrm{P}_{\text {flux }}$ decreases significantly with increasing feed water salt concentration. Notice that, the $3 \mathrm{D}$ response surfaces obtained by the two models were similar, due to $\mathrm{P}_{\text {flux }}$ being almost linear in all the input data range.

On the other hand, in Fig. 882, 4 and 6, and in Fig. 92 2, 4 and 6 the effects of $\mathrm{S}, \mathrm{T}_{\text {evap }}, \mathrm{T}_{\text {cond }}$ and $\mathrm{F}$ on the STEC predicted by the RSM and ANN models are shown. In this case, the opposite behaviour than in $\mathrm{P}_{\text {flux }}$ can be observed, STEC augments when increasing feed water salt concentration. Therefore, an increase in the salinity implies a decrease in thermal efficiency. Besides, some differences can be seen in the 3D response surfaces of both models. RSM model 
345 provides almost linear surfaces for the whole input data range, whereas ANN model provides nonlinear surfaces which represent in a more accurate way the behaviour of STEC observed from experimental data (see Appendix A). In addition, ANN model takes into consideration the influence of $\mathrm{T}_{\text {cond }}$ and $\mathrm{F}$ in the response (see Fig. 9.4 and 6), whereas RSM model does not consider these 350 variables (see Eq. 10) as was commented before.

According to the results obtained, different interaction effects can be seen among the input variables. Considering $\mathrm{T}_{\text {evap }}$ and $\mathrm{S}$, the increase of $\mathrm{T}_{\text {evap }}$ yields to an increase of the performance, namely, an increase of $\mathrm{P}_{\text {flux }}$ and a decrease of STEC, and this effect is stronger the higher the $\mathrm{S}$ values. The increase of S leads 355 to a decrease of the performance and this effect is stronger for smaller $T_{\text {evap }}$. Regarding the interaction effect between $\mathrm{F}$ and $\mathrm{S}$, an increase of $\mathrm{F}$ at different $\mathrm{S}$ values causes an enhancement of $\mathrm{P}_{\text {flux }}$. However, the effect of increasing $\mathrm{F}$ on STEC depends on S. For a salinity value of $35 \mathrm{~g} / \mathrm{L}$, an increase of $\mathrm{F}$ causes a negative effect on STEC, while for high $\mathrm{S}$ values, an increase of $\mathrm{F}$ produces the ${ }_{360}$ contrary effect. This is because at high $\mathrm{S}$ and low $\mathrm{F}$, the permeate production decreases at a higher rate than the decrease of the external heat necessary by working with a low F. Finally, the effect of $\mathrm{T}_{\text {cond }}$ on the $\mathrm{P}_{\text {flux }}$ is negative. An increase of this variable, yields to a decrease of the driving force, diminishing $\mathrm{P}_{\text {flux }}$ and this effect is stronger for high S. Regarding the STEC, at a salinity 365 of $35 \mathrm{~g} / \mathrm{L}$, an increase of $\mathrm{T}_{\text {cond }}$ favours the decline of the STEC, however, at high $\mathrm{S}$ values, the increase of $\mathrm{T}_{\text {cond }}$ leads to an increase of STEC because the decrease of $\mathrm{P}_{\text {flux }}$ at high $\mathrm{S}$ is more pronounced.

From an optimization point of view, two interesting conclusions can be drawn. Firstly, in Fig. 9f6 it can be observed how STEC decreases at low $370 \mathrm{~F}$ when $\mathrm{S}$ is in a low-medium range, and then, at high S, STEC has an almost curvilinear behaviour with respect $\mathrm{F}$ where the minimum value is located around $500 \mathrm{~L} / \mathrm{h}$. Secondly, it can be observed that the STEC does not present large variations with respect to $T_{\text {evap }}$ at low $\mathrm{S}$, around $80 \mathrm{kWh} / \mathrm{m}^{3}$ at $500 \mathrm{~L} / \mathrm{h}$ (see Fig. 9f1). However, at high salinity concentrations (i.e. $140 \mathrm{~g} / \mathrm{L}$ ), the influence 375 is remarkable, around $500 \mathrm{kWh} / \mathrm{m}^{3}$ at $500 \mathrm{~L} / \mathrm{h}$ (see Fig. 9-1). This fact can be very relevant in solar powered batch operations since the result of an optimization problem with a time horizon of one day could be: working at low $\mathrm{T}_{\text {evap }}$ at low salinity concentrations and storing thermal energy to be able to operate at high temperature, significantly improving performance, when high salinity 380 ranges are reached. 


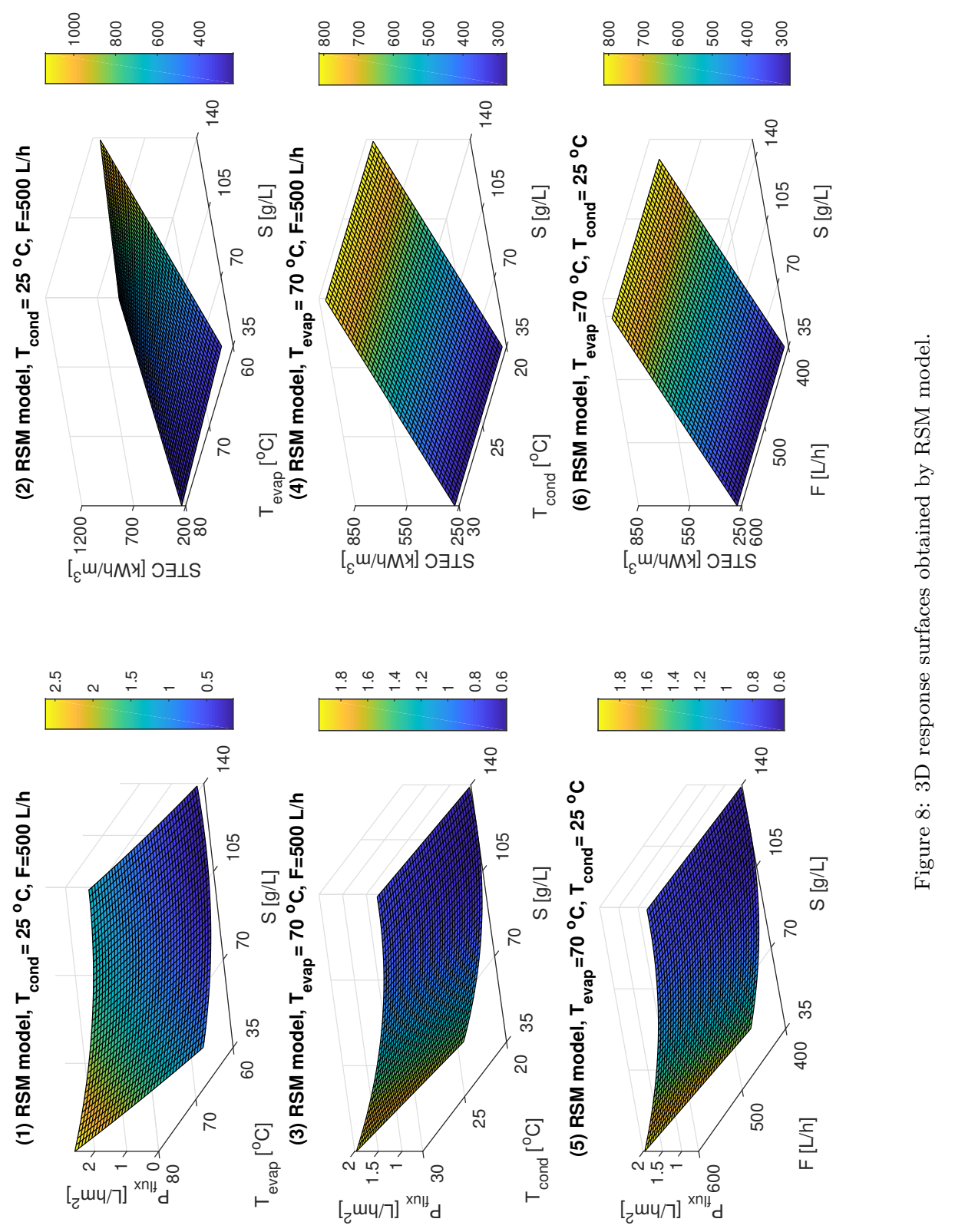




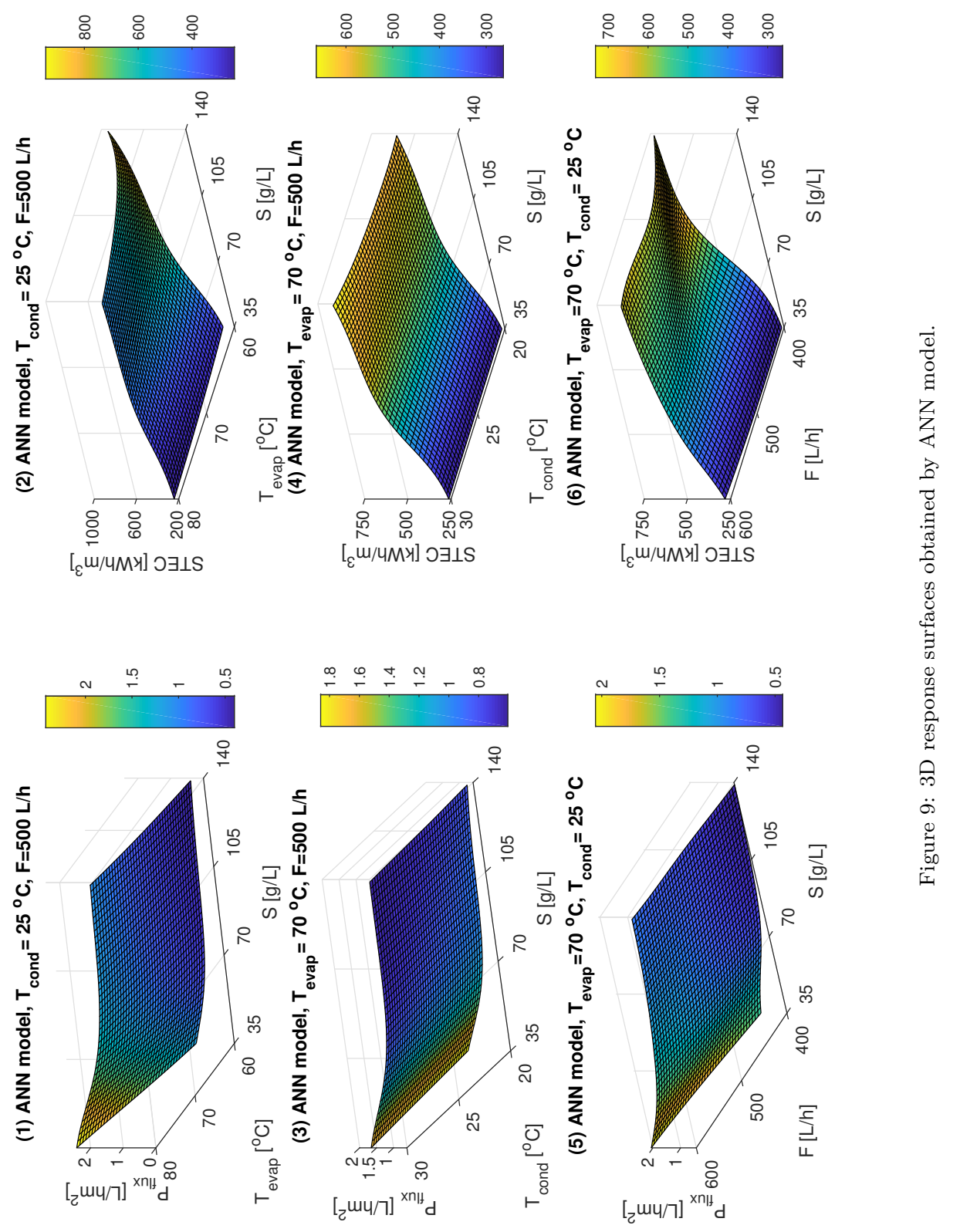




\subsection{Multi-objective optimization}

Once the models were developed, validated and compared, a multi-objective optimization was carried out using NSGA-II algorithm. The objective was to find a set of solutions that ensure a trade-off between the two performance parameters (maximizing $\mathrm{P}_{\text {flux }}$ and minimizing STEC), that require contrary operating conditions in some variables such as $\mathrm{T}_{\text {cond }}$ and $\mathrm{F}$. This set of optimal solution is known as Pareto Front or nondominant solutions. Thus, two optimization cases were proposed according to the levels of feed water salt concentration that can be reached when performing batch operation for desalting $\mathrm{RO}$ brines. In the first optimization problem, the feed water salt concentration was fixed at $70 \mathrm{~g} / \mathrm{L}$, whereas in the second optimization problem, the feed water salt concentration was fixed at $105 \mathrm{~g} / \mathrm{L}$. Notice that the optimized variables in both cases are $\mathrm{T}_{\text {cond }}, \mathrm{T}_{\text {evap }}$, and $\mathrm{F}$, since they can be easily manipulated to achieve the desired performance. The optimization was carried out using only

395 the ANN model as it takes into account all the input variables for the two performance parameters, as was commented in the previous section. The results obtained for both optimization cases are reported in Fig. 10 and Tab. 10. In addition, three experimental runs randomly selected were performed in order to validate the optimal points obtained in the two optimization problems (see Tab. 111).
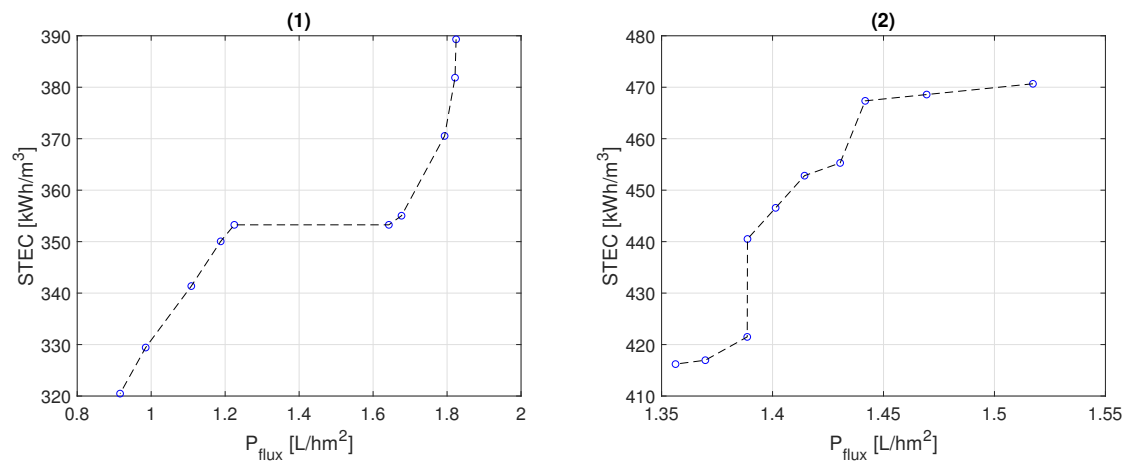

Figure 10: Pareto fronts of the two optimization cases. (1) Results related to optimization problem 1 , and (2) results related to optimization problem 2.

Attending to the results, Tab. 10 shows that different operating conditions are required in some of the parameters depending on the level of feed water salinity. Notice that the pareto fronts must be analyzed by assigning different importance for responses, according to the specific desirability of the applica-

405 tion. In general, it can be seen that in the two studied cases, for applications that require higher distillate production it is better to operate with larger $\mathrm{F}$ and smaller $\mathrm{T}_{\text {cond }}$. However, if the thermal efficiency is the decisive factor in the application, it is better to operate with smaller $\mathrm{F}$ and larger $\mathrm{T}_{\text {cond }}$ at the feed water salinity of $70 \mathrm{~g} / \mathrm{L}$. On the other hand, at the feed water salinity of $105 \mathrm{~g} / \mathrm{L}$, larger $\mathrm{T}_{\text {cond }}$ and larger $\mathrm{F}$ are required. It is also important to remark that in the 


\begin{tabular}{cccccc}
\hline Run & $\mathrm{T}_{\text {cond }}\left({ }^{\circ} \mathrm{C}\right)$ & $\mathrm{T}_{\text {evap }}\left({ }^{\circ} \mathrm{C}\right)$ & $\mathrm{F}(\mathrm{L} / \mathrm{h})$ & $\mathrm{STEC}_{\text {pred }}\left(\mathrm{kWh} / \mathrm{m}^{3}\right)$ & $\mathrm{P}_{\text {flux }, \text { pred }}\left(\mathrm{L} /\left(\mathrm{h} \cdot \mathrm{m}^{2}\right)\right)$ \\
\hline \multicolumn{5}{c}{ Pareto front values of optimization problem 1} \\
\hline 1 & 20.00 & 80.00 & 600.00 & 389.31 & 1.83 \\
2 & 20.31 & 80.00 & 577.04 & 381.85 & 1.82 \\
3 & 21.09 & 80.00 & 557.45 & 370.53 & 1.79 \\
4 & 28.81 & 80.00 & 599.86 & 355.03 & 1.67 \\
5 & 30.00 & 80.00 & 597.49 & 353.26 & 1.64 \\
6 & 26.64 & 80.00 & 436.35 & 353.26 & 1.22 \\
7 & 26.84 & 80.00 & 426.97 & 350.05 & 1.18 \\
8 & 26.85 & 80.00 & 401.38 & 341.36 & 1.10 \\
9 & 29.67 & 80.00 & 412.29 & 329.42 & 0.98 \\
10 & 30.00 & 80.00 & 400.00 & 320.47 & 1.91 \\
\hline \multicolumn{5}{c}{ Pareto front values of optimization problem 2} & 1.46 \\
\hline 1 & 20.00 & 80.00 & 600.00 & 470.67 & 1.43 \\
2 & 21.02 & 80.00 & 598.73 & 468.58 & 1.41 \\
3 & 21.49 & 80.00 & 595.28 & 467.35 & 1.40 \\
4 & 20.62 & 80.00 & 556.64 & 455.28 & 1.38 \\
5 & 21.11 & 80.00 & 557.07 & 452.81 & 1.38 \\
6 & 21.40 & 80.00 & 548.95 & 446.56 & 1.36 \\
7 & 21.33 & 80.00 & 532.78 & 440.51 & \\
8 & 30.00 & 80.00 & 600.00 & 421.48 & \\
9 & 29.86 & 80.00 & 585.48 & 416.96 & \\
10 & 30.00 & 80.00 & 580.10 & 416.20 & \\
\hline
\end{tabular}

Table 10: Values of the Pareto fronts obtained by ANN model for both optimization problems.

\begin{tabular}{ccccc}
\hline $\begin{array}{c}\text { Run in the } \\
\text { optimization }\end{array}$ & $\begin{array}{c}\mathrm{STEC}_{\text {pred }} \\
\left(\mathrm{kWh} / \mathrm{m}^{3}\right)\end{array}$ & $\begin{array}{c}\mathrm{P}_{\text {flux,pred }} \\
\left(\mathrm{L} /\left(\mathrm{h} \cdot \mathrm{m}^{2}\right)\right)\end{array}$ & $\begin{array}{c}\mathrm{STEC}_{\exp } \\
\left(\mathrm{kWh} / \mathrm{m}^{3}\right)\end{array}$ & $\begin{array}{c}\mathrm{P}_{\text {flux }, \exp } \\
\left(\mathrm{L} /\left(\mathrm{h} \cdot \mathrm{m}^{2}\right)\right)\end{array}$ \\
\hline \multicolumn{5}{c}{ Confirmation runs of optimization problem 1 } \\
\hline 3 & 370.53 & 1.79 & 361.50 & 1.79 \\
6 & 353.26 & 1.22 & 360.10 & 1.18 \\
8 & 341.36 & 1.10 & 357.15 & 1.02 \\
\hline \multicolumn{5}{c}{ Confirmation runs of optimization problem 2} \\
\hline 4 & 470.67 & 1.51 & 474.97 & 1.48 \\
5 & 455.28 & 1.43 & 456.08 & 1.46 \\
\hline
\end{tabular}

Table 11: Validation of the optimal operating points.

two optimization problems, the inlet evaporator channel temperature is at the maximum $\left(80^{\circ} \mathrm{C}\right)$ for all the pareto solutions. Nevertheless, in real solar powered operations, this temperature will be limited by the irradiance conditions at every moment and, therefore, the optimal operating conditions can be obtained by modifying only $\mathrm{T}_{\text {cond }}$ and $\mathrm{F}$. It should be pointed out that $\mathrm{T}_{\text {cond }}$ steadily increases when performing batch operations, but it could be manipulated using 
cooling devices in order to work in the optimal operating points, thus increasing MD module performance.

Moreover, Tab. 12 shows the salt rejection factor (SRF) for each of the studied salinities. For the three salinities, the SRF was close to $100 \%$, confirming that in this case, in accordance with the MD fundamentals, the operating conditions do not affect the salinity of permeate [44].

\begin{tabular}{ccccc}
\hline $\mathrm{S}(\mathrm{g} / \mathrm{L})$ & $\mathrm{T}_{\text {cond }}\left({ }^{\circ} \mathrm{C}\right)$ & $\mathrm{T}_{\text {evap }}\left({ }^{\circ} \mathrm{C}\right)$ & $\mathrm{F}(\mathrm{L} / \mathrm{h})$ & $\mathrm{SRF}(\%)$ \\
\hline 35 & 20.00 & 80.00 & 583.00 & $99.99 \%$ \\
70 & 21.10 & 80.00 & 558.00 & $99.99 \%$ \\
105 & 20.60 & 80.00 & 557.45 & $99.99 \%$ \\
\hline
\end{tabular}

Table 12: Salt rejection factor for each salinity.

\section{Conclusion}

425

Response Surface Methodology (RSM) and Artificial Neural Networks (ANN) were used for modeling the performance of a commercial-scale PGMD module, under the operating conditions required by one of its possible potential industrial implementation: desalting brines from RO plants. The independent variables chosen for the models were the condenser inlet temperature $\left(20-30{ }^{\circ} \mathrm{C}\right)$, the evaporator inlet temperature $\left(60-80{ }^{\circ} \mathrm{C}\right)$, the feed flow rate $(400-600 \mathrm{~L} / \mathrm{h})$ and the feed water salt concentration $(35-140 \mathrm{~g} / \mathrm{L})$, while permeate flux $\left(\mathrm{L} /\left(\mathrm{h} \cdot \mathrm{m}^{2}\right)\right)$ and Specific Thermal Energy Consumption (STEC, $\mathrm{kWh} / \mathrm{m}^{3}$ ) were selected as predicted variables. The prediction abilities of the two modeling tools were compared with further experimental data. In addition, the optimal operating 435 conditions (maximizing and minimizing $\mathrm{P}_{\text {flux }}$ and STEC respectively) for two of the feed salinity concentrations $(70$ and $105 \mathrm{~g} / \mathrm{L})$ that can be reached when performing batch operation for desalting RO brines were determined.

Regarding the models, the ANN model achieved higher accuracy in predicting the responses, specially in the STEC case. This fact can be explained since the feed water salt concentration affects the STEC on a nonlinear way, which cannot be well represented by a quadratic equation. Therefore, ANN model is shown to be more adequate than RSM for developing models in which the feed water salt concentration is considered as an input. However, it should be also commented that it required more experimental data.

The multi-objetive optimization carried out revealed that, depending of the level of feed water salinity, different operating conditions are required in some of the parameters. Therefore, real time multi-objective optimization could be essential for performing batch operations aimed at desalting RO brines, specially when the MD facility is powered by solar energy.

In future works, the models presented in this paper will be used for developing optimization algorithms able to perform optimal designs of a solar powered MD facility to be integrated in a RO plant. In the same way, models will be 
used for optimizing the solar powered operation of the MD module in batch mode operation.

\section{Acknowledgments}

This work has been funded by the National $\mathrm{R}+\mathrm{D}+\mathrm{i}$ Plan Projects DPI201456364-C2-1/2-R and DPI2017-85007-R of the Spanish Ministry of Economy, Industry and Competitiveness and ERDF funds. 


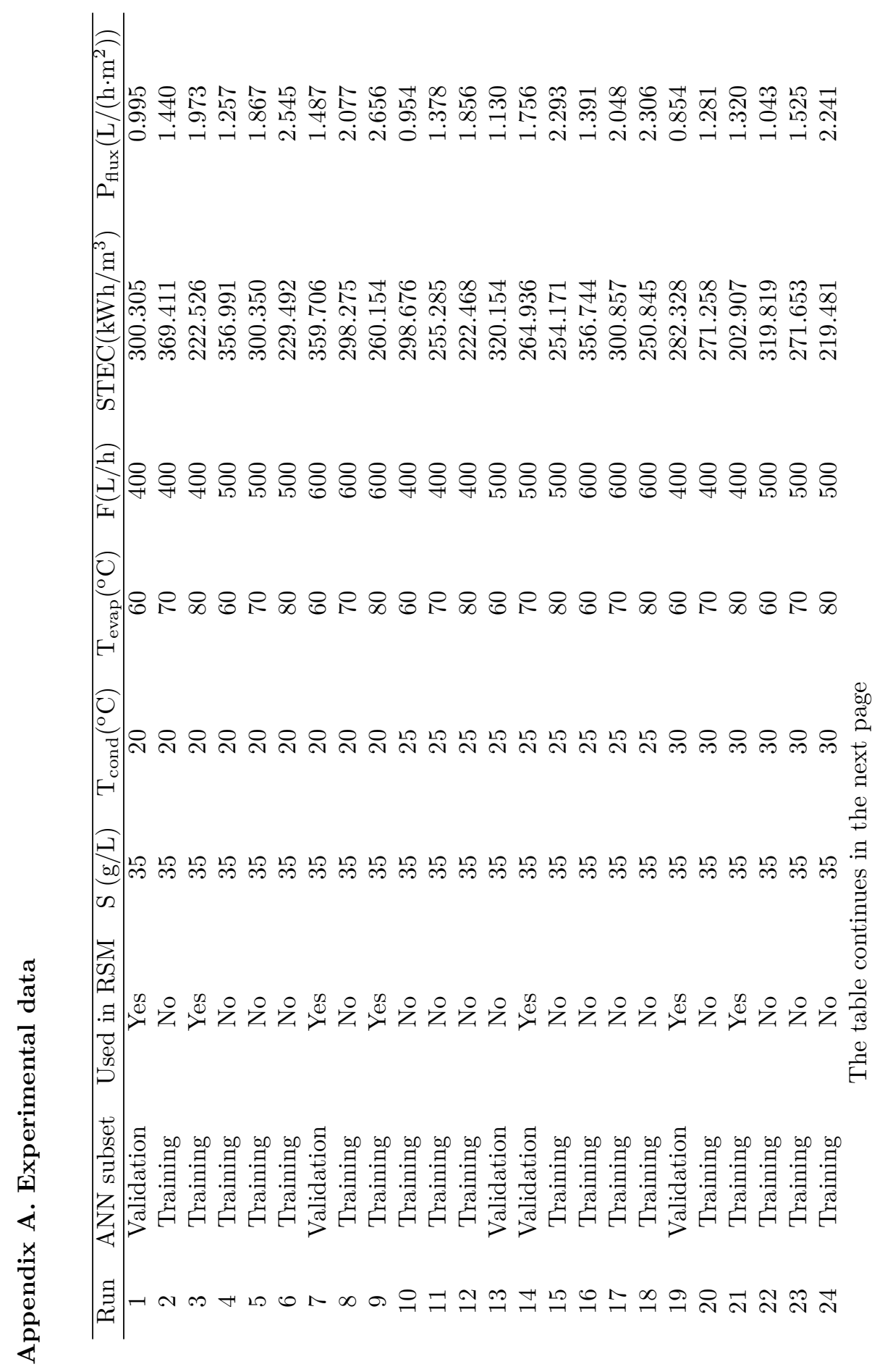




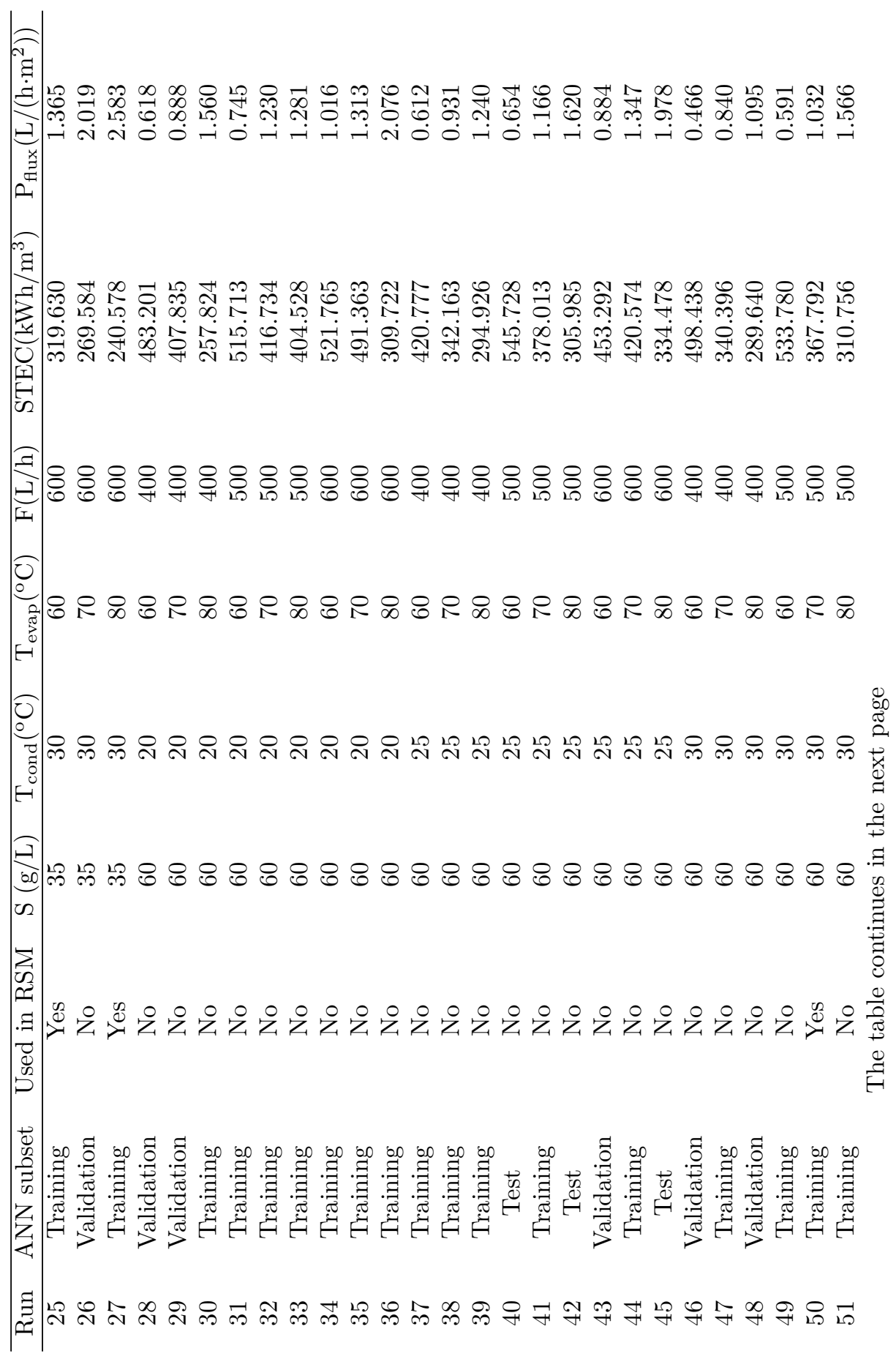




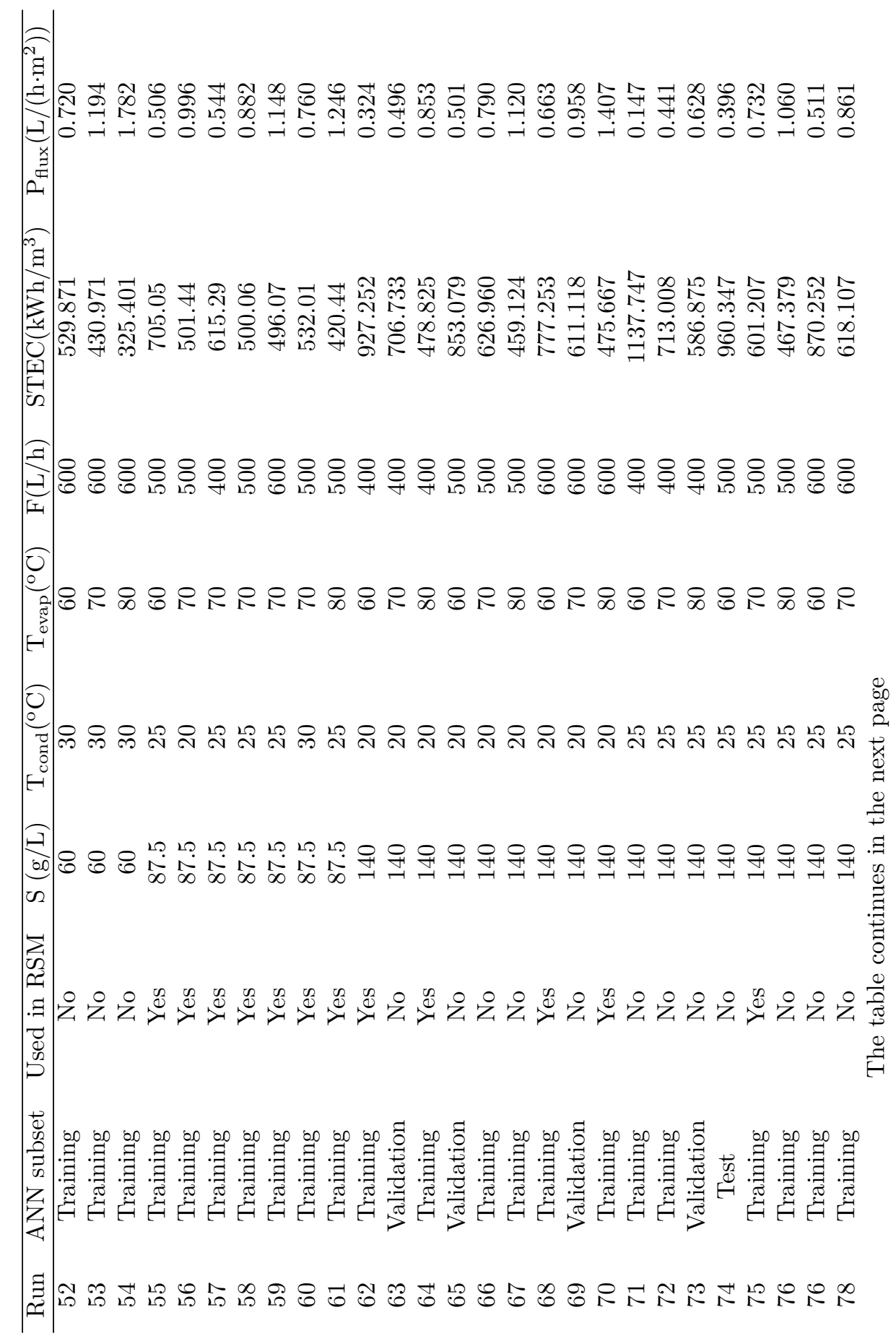




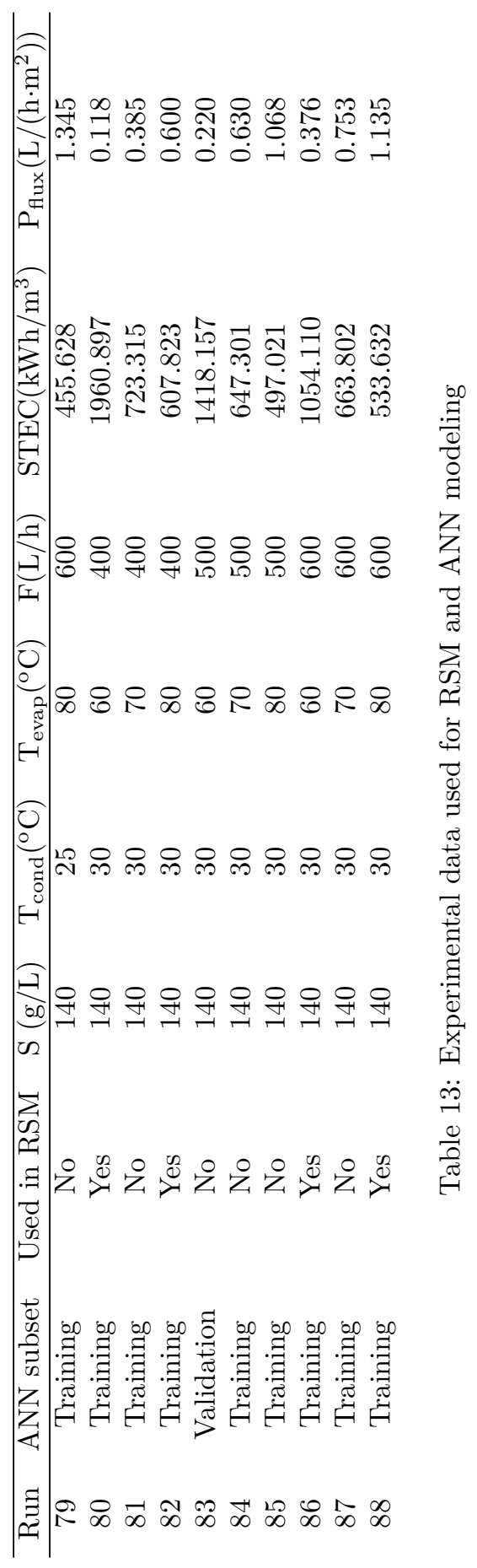


[1] J. P. Mericq, S. Laborie, C. Cabassud, Vacuum membrane distillation of seawater reverse osmosis brines, Water Research 44 (2010) 5260-5273.

[2] D. Qu, J. Wang, B. Fan, Z. Luan, D. Hou, Study on concentrating primary reverse osmosis retentate by direct contact membrane distillation, Desalination 247 (2009) 540-550.

[3] C. R. Martinetti, A. E. Childress, T. Y. Cath, High recovery of concentrated RO brines using forward osmosis and membrane distillation, Journal of membrane science 331 (2009) 31-39.

[4] J. Sanmartino, M. Khayet, M. García-Payo, H. El-Bakouri, A. Riaza, Treatment of reverse osmosis brine by direct contact membrane distillation: Chemical pretreatment approach, Desalination 420 (2017) 79-90.

[5] A. Alkhudhiri, N. Darwish, N. Hilal, Membrane distillation: a comprehensive review, Desalination 287 (2012) 2-18.

[6] M. Khayet, Solar desalination by membrane distillation: Dispersion in energy consumption analysis and water production costs (a review), Desalination 308 (2013) 89-101.

[7] E. Drioli, A. Ali, F. Macedonio, Membrane distillation: Recent developments and perspectives, Desalination 356 (2015) 56-84.

[8] N. Thomas, M. O. Mavukkandy, S. Loutatidou, H. A. Arafat, Membrane distillation research \& implementation: Lessons from the past five decades, Separation and Purification Technology 189 (2017) 108-127.

[9] M. Khayet, C. Cojocaru, A. Baroudi, Modeling and optimization of sweeping gas membrane distillation, Desalination 287 (2012) 159-166.

[10] M. Khayet, C. Cojocaru, Artificial neural network modeling and optimization of desalination by air gap membrane distillation, Separation and Purification Technology 86 (2012) 171-182.

[11] M. Khayet, C. Cojocaru, Artificial neural network model for desalination by sweeping gas membrane distillation, Desalination 308 (2013) 102-110.

[12] A. Ruiz-Aguirre, J. Andrés-Mañas, J. Fernández-Sevilla, G. Zaragoza, Modeling and optimization of a commercial permeate gap spiral wound membrane distillation module for seawater desalination, Desalination 419 (2017) 160-168.

[13] J. D. Gil, L. Roca, A. Ruiz-Aguirre, G. Zaragoza, M. Berenguel, Optimal operation of a solar membrane distillation pilot plant via nonlinear model predictive control, Computers \& Chemical Engineering 109 (2018) 151-165. 
[14] R. Porrazzo, A. Cipollina, M. Galluzzo, G. Micale, A neural networkbased optimizing control system for a seawater-desalination solar-powered membrane distillation unit, Computers \& Chemical Engineering 54 (2013) 79-96.

[15] Y.-H. Chen, Y.-W. Li, H. Chang, Optimal design and control of solar driven air gap membrane distillation desalination systems, Applied Energy 100 (2012) 193-204.

[16] I. Hitsov, T. Maere, K. De Sitter, C. Dotremont, I. Nopens, Modelling approaches in membrane distillation: a critical review, Separation and Purification Technology 142 (2015) 48-64.

[17] M. Khayet, C. Cojocaru, M. Essalhi, Artificial neural network modeling and response surface methodology of desalination by reverse osmosis, Journal of Membrane Science 368 (2011) 202-214.

[18] A. E. Khalifa, D. U. Lawal, Application of response surface and Taguchi optimization techniques to air gap membrane distillation for water desalination: A comparative study, Desalination and Water Treatment 57 (2016) 28513-28530.

[19] S. T. Bouguecha, A. Boubakri, S. E. Aly, M. H. Al-Beirutty, M. M. Hamdi, Optimization of permeate flux produced by solar energy driven membrane distillation process using central composite design approach, Water Science and Technology 74 (2016) 87-98.

[20] T. Mohammadi, P. Kazemi, M. Peydayesh, Optimization of vacuum membrane distillation parameters for water desalination using Box-Behnken design, Desalination and Water Treatment 56 (2015) 2306-2315.

520 [21] A. Boubakri, A. Hafiane, S. A. T. Bouguecha, Application of response surface methodology for modeling and optimization of membrane distillation desalination process, Journal of Industrial \& Engineering Chemistry 20 (2014) 3163-3169.

[22] M. Khayet, C. Cojocaru, Air gap membrane distillation: Desalination, modeling and optimization, Desalination 287 (2012) 138-145.

[23] H. Chang, J.-S. Liau, C.-D. Ho, W.-H. Wang, Simulation of membrane distillation modules for desalination by developing user's model on Aspen Plus platform, Desalination 249 (2009) 380-387.

[24] M. Khayet, C. Cojocaru, C. García-Payo, Application of response surface methodology and experimental design in direct contact membrane distillation, Industrial \& Engineering Chemistry Research 46 (2007) 5673-5685.

[25] D. Cheng, W. Gong, N. Li, Response surface modeling and optimization of direct contact membrane distillation for water desalination, Desalination 394 (2016) 108-122. 
[26] Q. He, P. Li, H. Geng, C. Zhang, J. Wang, H. Chang, Modeling and optimization of air gap membrane distillation system for desalination, Desalination 354 (2014) 68-75.

[27] W. Cao, Q. Liu, Y. Wang, I. M. Mujtaba, Modeling and simulation of VMD desalination process by ANN, Computers \& Chemical Engineering 84 (2016) 96-103.

[28] M. Tavakolmoghadam, M. Safavi, An optimized neural network model of desalination by vacuum membrane distillation using genetic algorithm, Procedia Engineering 42 (2012) 106-112.

[29] S. Shirazian, M. Alibabaei, Using neural networks coupled with particle swarm optimization technique for mathematical modeling of air gap membrane distillation (AGMD) systems for desalination process, Neural Computing and Applications 28 (2017) 2099-2104.

[30] D. Cheng, N. Li, J. Zhang, Modeling and multi-objective optimization of vacuum membrane distillation for enhancement of water productivity and thermal efficiency in desalination, Chemical Engineering Research and Design 132 (2018) 697-713.

[31] Y. Zhou, M. Huang, Q. Deng, T. Cai, Combination and performance of forward osmosis and membrane distillation (FO-MD) for treatment of high salinity landfill leachate, Desalination 420 (2017) 99-105.

[32] N. U. Kumar, A. Martin, Experimental modeling of an air-gap membrane distillation module and simulation of a solar thermal integrated system for water purification, Desalination and Water Treatment 84 (2017) 123-134.

[33] J. D. Gil, L. Roca, G. Zaragoza, M. Berenguel, A feedback control system with reference governor for a solar membrane distillation pilot facility, Renewable Energy 120 (2018) 536-549.

[34] H. C. Duong, P. Cooper, B. Nelemans, T. Y. Cath, L. D. Nghiem, Evaluating energy consumption of air gap membrane distillation for seawater desalination at pilot scale level, Separation and Purification Technology 166 (2016) 55-62.

[35] E. Guillén-Burrieza, G. Zaragoza, S. Miralles-Cuevas, J. Blanco, Experimental evaluation of two pilot-scale membrane distillation modules used for solar desalination, Journal of Membrane Science 409 (2012) 264-275.

[36] G. Zaragoza, A. Ruiz-Aguirre, E. Guillén-Burrieza, Efficiency in the use of solar thermal energy of small membrane desalination systems for decentralized water production, Applied Energy 130 (2014) 491-499.

[37] W. J. Hill, W. G. Hunter, A review of response surface methodology: a literature survey, Technometrics 8 (1966) 571-590. 
[38] G. E. Box, K. B. Wilson, On the experimental attainment of optimum conditions, in: Breakthroughs in Statistics, Springer, 1992, pp. 270-310.

575 [39] L. Stahle, S. Wold, et al., Analysis of variance (ANOVA), Chemometrics and Intelligent Laboratory Systems 6 (1989) 259-272.

[40] M. H. Beale, M. T. Hagan, H. B. Demuth, Neural Network Toolbox: User's Guide (Version 10.0), 2017.

[41] M. T. Hagan, H. B. Demuth, Neural networks for control, in: American Control Conference, 1999. Proceedings of the 1999, volume 3, IEEE, 1999, pp. $1642-1656$.

[42] H. B. Demuth, M. H. Beale, O. De Jess, M. T. Hagan, Neural network design, PWS Publishing Co., 2014.

[43] K. Deb, A. Pratap, S. Agarwal, T. Meyarivan, A fast and elitist multiobjective genetic algorithm: NSGA-II, IEEE Transactions on Evolutionary Computation 6 (2002) 182-197.

[44] D. Winter, J. Koschikowski, M. Wieghaus, Desalination using membrane distillation: Experimental studies on full scale spiral wound modules, Journal of Membrane Science 375 (2011) 104-112. 